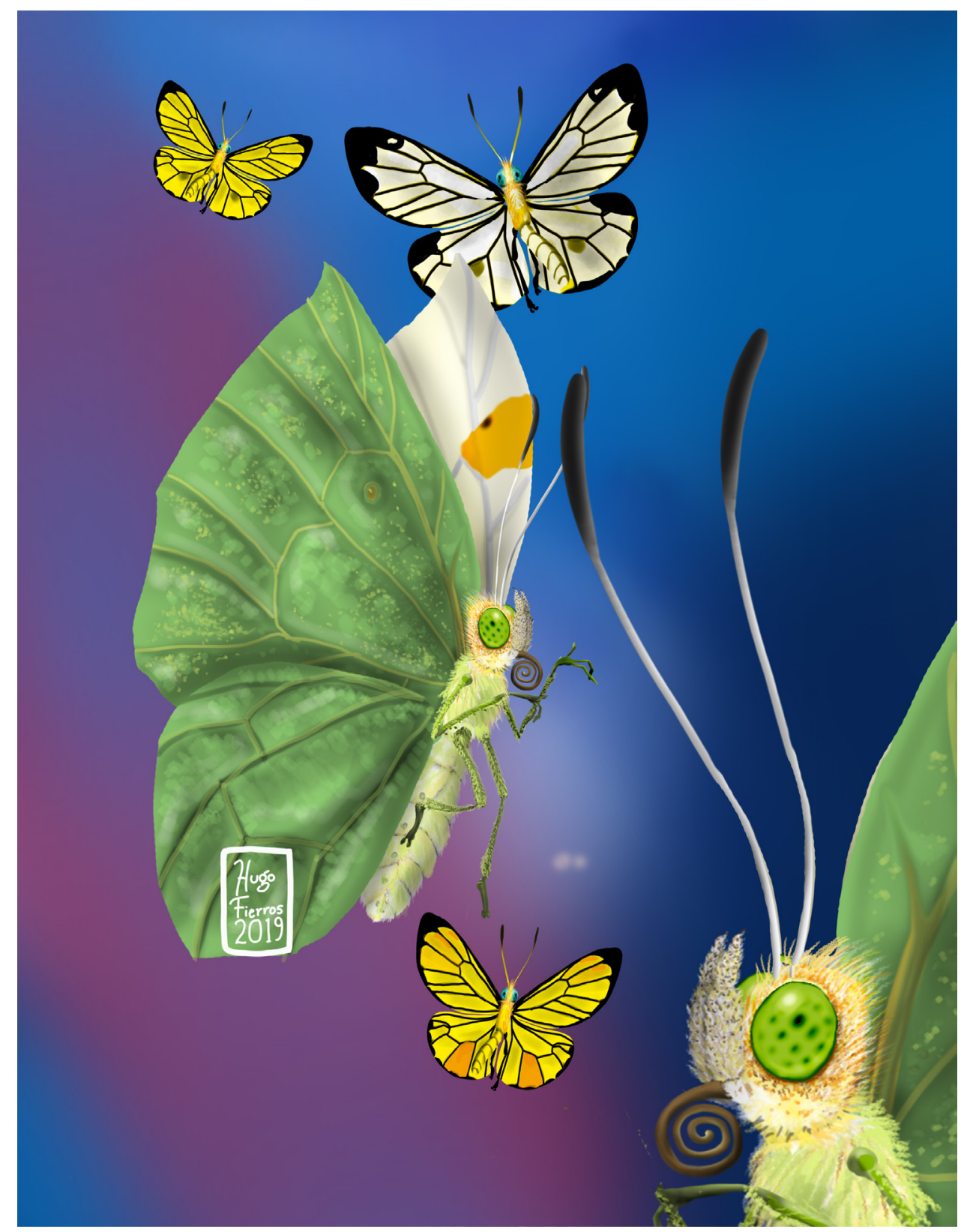

Dugesiana, Año 26, No. 2, julio 2019-diciembre 2019 (segundo semestre de 2019), es una publicación semestral, editada por la Universidad de Guadalajara, a través del Centro de Estudios en Zoología, por el Centro Universitario de Ciencias Biológicas y Agropecuarias. Camino Ramón Padilla Sánchez \# 2100, Nextipac, Zapopan, Jalisco, Tel. 37771150 ext. 33218, http://148.202.248.171/dugesiana/index.php/DUG/index, glenusmx@gmail.com. Editor responsable: José Luis Navarrete Heredia. Reserva de Derechos al Uso Exclusivo 04-2009-062310115100203, ISSN: 2007-9133, otorgados por el Instituto Nacional del Derecho de Autor. Responsable de la última actualización de este número: José Luis Navarrete Heredia, Editor y Ana Laura González-Hernández, Asistente Editorial. Fecha de la última modificación 25 de julio 2019, con un tiraje de un ejemplar.

Las opiniones expresadas por los autores no necesariamente reflejan la postura del editor de la publicación.

Queda estrictamente prohibida la reproducción total o parcial de los contenidos e imágenes de la publicación sin previa autorización de la Universidad de Guadalajara. 
Artículo

\title{
Las hormigas legionarias de Jalisco (Hymenoptera: Formicidae: Dorylinae): lista comentada y claves
}

\section{The army ants of Jalisco, Mexico (Hymenoptera: Formicidae: Dorylinae): annotated checklist and identification keys}

\author{
Carlos E. Alatorre-Bracamontes ${ }^{1 *}$, Miguel Vásquez-Bolaños ${ }^{1}$, Gabriela Castaño-Meneses ${ }^{2}$, José Luis Navarrete- \\ Heredia $^{1}$ y John E. Lattke ${ }^{3}$ \\ ${ }^{1}$ Entomología, Centro de Estudios en Zoología, Centro Universitario de Ciencias Biológicas y Agropecuarias, \\ Universidad de Guadalajara, Km. 15.5 Carr. Nogales, Las Agujas, Zapopan, Jalisco 45110, México. Apdo. Postal \\ 134. *pseudomyrmo@gmail.com; ${ }^{2}$ Ecología de Artrópodos en Ambientes Extremos, Unidad Multidisciplinaria de \\ Docencia e Investigación, Facultad de Ciencias, UNAM, Campus Juriquilla, Boulevard Juriquilla 3001, Querétaro \\ 76230, México; ${ }^{3}$ Departamento de Zoologia, Universidade Federal do Paraná, Caixa Postal 19020, 81531-980, \\ Curitiba, Paraná, Brasil.
}

RESUMEN

Se presentan una lista comentada de las especies de hormigas legionarias del estado de Jalisco y occidente de México, así como claves para la determinación de soldados y obreras. Este trabajo se basó en muestreos realizados en 17 localidades de 14 municipios de Jalisco, así como en la revisión de especímenes depositados en cuatro colecciones entomológicas nacionales. Se examinaron 21,167 ejemplares de hormigas legionarias, donde 18,344 correspondieron a material depositado en las colecciones. Para cada especie, se elaboró una lámina con los principales caracteres diagnósticos empleados en las claves dicotómicas. Los ejemplares en mejores condiciones, con excepción de Neivamyrmex pauxillus y N. pilosus, cuyos esquemas fueron redibujados a partir de fotografías obtenidas del sitio AntWeb (2015), se eligieron para elaborar las láminas. Se incluyen 21 especies, en la clave y la lista comentada, agrupadas en cuatro géneros: Eciton, Labidus, Neivamyrmex y Nomamyrmex. Se documentan tres primeros nuevos registros para Jalisco: Neivamyrmex halidaii (Shuckard, 1840), N. impudens (Mann, 1922) y N. pauxillus (Wheeler, 1903).

Palabras Clave: determinación, diversidad, obreras y soldados, Occidente de México.

\begin{abstract}
An annotated checklist of species of army ants for Jalisco state and western Mexico and a key for the identification of soldiers and workers are presented. This work was carried out based on field sampling of 17 locations in 14 municipalities of Jalisco, and review of specimens deposited in four national entomological collections. 21,167 specimens of army ants were examined, of which 18,344 correspond to material deposited in entomological collections visited. For each species of army ant, a sheet was elaborated that illustrates its main diagnostic characters, which were used for the dichotomous key. The specimens in better were chosen to elaborate the plate, with the exception of Neivamyrmex pauxillus and N. pilosus whose schemes were redrawn from photographs from AntWeb site (2015). The key and checklist of army ants for Jalisco State includes a total of 21 species grouped into four genera: Eciton, Labidus, Neivamyrmex, and Nomamyrmex. Three first new records for Jalisco are included: Neivamyrmex halidaii (Shuckard, 1840), N. impudens (Mann, 1922) and N. pauxillus (Wheeler, 1903).
\end{abstract}

Key Words: determination, diversity, soldiers and workers, western Mexico.

Las hormigas legionarias también son conocidas en México como cazadoras, pasaderas, moritas o marabuntas, expresiones que refieren a los hábitos depredadores que las caracterizan (Vásquez-Bolaños 1996, 2008). Están agrupadas en una sola subfamilia: Dorylinae, que actualmente incluye al clado que agrupa a las hormigas legionarias del Viejo y Nuevo Mundo (Brady et al. 2014).

Desde el punto de vista morfológico, las hormigas dorilinas comparten las siguientes sinapomorfías: presencia de una glándula metatibial (con excepción de las antiguas Leptanilloidinae); así como el orificio de la glándula metapleural cubierto dorsalmente por una lámina cuticular y un pigidio modificado (Bolton 1990, 2003). También, tienen en común otros caracteres morfológicos: inserciones antenales expuestas en vista frontal; lóbulos frontales ausentes; ojos ausentes en los soldados y obreras, representados por una mancha amarilla bajo la cutícula o un sólo omatidio; espiráculos propodeales situados muy 
arriba, en los costados del propodeo; así como, presencia de un aguijón bien desarrollado y funcional (Palacio 2003).

Son abundantes en tierras tropicales y bosques húmedos, en donde sus comunidades pueden estar conformadas por más de 20 especies simpátricas (O’Donnell et al. 2007). Son depredadoras formidables, pues sus batidas de cacería están compuestas por cientos de miles de individuos que se desplazan en busca de presas vivas, sobre las cuales se desbordan y matan al instante de ser localizadas (Kronauer 2009). Además, el tamaño de una colonia suele ser muy grande; de hecho, se documentó que la población de un nido del género Eciton alcanzó entre cinco y más de diez millones de individuos (Jaffé 1993; Ríos-Casanova 2014).

$\mathrm{Su}$ distribución está confinada a los trópicos y subtrópicos de todo el mundo (Gottwald 1979). En nuestro país, principalmente se les encuentra en las regiones bajas y medias tropicales, donde algunas especies alcanzan las tierras templadas y áridas del norte (Watkins 1982, 1986, 1988, 1990; Bolton et al. 2006; Vásquez-Bolaños 2011, 2015; Ríos-Casanova 2014).

Las verdaderas hormigas legionarias del Nuevo Mundo se agrupan en una tribu, Dorylini, cinco géneros, así como 175 especies y subespecies distribuidas de la siguiente forma (Brady et al. 2014; AntWeb 2016a): Cheliomyrmex (cuatro especies), Eciton (12 especies, 17 subespecies), Labidus (siete especies, dos subespecies), Neivamyrmex (128 especies, una subespecie) y Nomamyrmex (dos especies y dos subespecies). De acuerdo con los registros de Ríos-Casanova (2014), Varela-Hernández y CastañoMeneses (2011), así como Vásquez-Bolaños (2015), 52 especies se presentan en México.

Los estudios sobre hormigas legionarias realizados en el país comprenden principalmente inventarios faunísticos regionales o estatales: Los Tuxtlas, Veracruz (Rojas y Cartas 1997, Quiroz-Robledo et al. 2002); Morelos (QuirozRobledo y Valenzuela-González 2004) y Jalisco (Watkins 1988). Solo Watkins (1982) publicó un trabajo que incluye a las especies de todo el país: The army ants of Mexico.

Especialmente para Jalisco, destacan los trabajos realizados por Watkins $(1986,1988)$ en la Estación de Biología Chamela y el de Vásquez-Bolaños (2008) para localidades en cuatro municipios del noroeste. Es importante destacar que solo los trabajos de Watkins (1982, 1988) incluyen claves para la determinación de especies de dorilinas, por lo que objetivo de este trabajo es presentar claves dicotómicas específicas para especies con distribución en el estado, con inclusión de ilustraciones y caracteres diagnósticos de fácil reconocimiento.

\section{MATERIAL Y MÉTODOS}

El área de influencia de la clave y lista comentada de especies incluye solo al estado de Jalisco, que se localiza en la región media occidental de México $\left(22^{\circ} 45^{\prime}\right.$ y $18^{\circ} 55^{\prime} \mathrm{N}$, $101^{\circ} 28^{\prime}$ y $105^{\circ} 42^{\prime} \mathrm{O}$ ). Sus $78,588 \mathrm{~km}^{2}$ de superficie lo ubican entre las regiones Neártica y Neotropical, así como en las provincias del Altiplano Mexicano (Sur), Sierra
Madre Occidental, Sierra Madre del Sur, Eje Volcánico Transmexicano, Depresión del Balsas y Costa del Pacífico (Morrone 2005; Morrone y Márquez 2008; Fig. 1a). Presenta bosque tropical caducifolio (BTC), de coníferas y encinos (BPE), tropical subcaducifolio (BTSC), mesófílo de montaña (BMM), espinoso, así como pastizal, matorral xerófilo y vegetación acuática (Rzedowski 2006; Fig. 1b).

Se realizaron recolectas no sistemáticas de nuevo material biológico, con la ayuda de pinzas entomológicas, entre julio de 2014 a noviembre de 2015, en 17 localidades de 14 municipios de Jalisco (Fig. 1). Adicionalmente, se emplearon 36 trampas: 18 de caída y 18 de una variación de la necrotrampa permanente NTP-80 cebada con calamar (Morón y Terrón 1984). En el bosque de maple de Talpa, así como en el Cerro de la Mesa en Tamazula de Gordiano, se utilizaron 16 trampas subterráneas cebadas con atún, calamar y miel. Las trampas operaron solo por un mes en cada sitio. Los ejemplares recolectados se depositaron en frascos con alcohol etílico al $70 \%$ y se depositaron en la Colección Entomológica del Centro de Estudios en Zoología de la Universidad de Guadalajara (CZUG) en Zapopan, Jalisco.

También, se obtuvieron registros de hormigas legionarias de Jalisco depositadas en la CZUG, en la Colección Entomológica de la Estación de Biología Chamela (EBCH) de la Universidad Nacional Autónoma de México (UNAM), además de la Colección de Hormigas del Laboratorio de Ecología y Sistemática de Microartrópodos (LESMA) de la Facultad de Ciencias de la UNAM y la Colección Nacional de Insectos (CNIN) del Instituto de Biología de la UNAM.

Para la clasificación taxonómica de Dorylinae, se siguió la propuesta presentada por Brady et al. (2014). La identificación de las especies se realizó con base en los trabajos de Watkins (1976, 1982, 1988), Snelling y Snelling (2007) y AntWeb (2015). Cada especie incluida en la lámina que se elaboró para apoyar a la clave dicotómica, fue ilustrada y sus caracteres diagnósticos resaltados: vellosidades, ornamentación, forma de los artejos antenales, perfil del mesosoma, espinas propodelaes, tamaño del peciolo y pospeciolo. Además, para la realización de los dibujos se eligieron ejemplares en buenas condiciones y preferentemente obreras. Solo Neivamyrmex pauxillus y $N$. pilosus fueron redibujados a partir de imágenes de AntWeb (2016b, c). Las especies del género Eciton se dibujaron a partir de los soldados. Eciton vagans angustatum se dibujó de una soldado menor. Las ilustraciones se realizaron con una cámara lúcida colocada en un microscopio Zeiss Stemi SV 6 y se digitalizaron con los programas Adobe Illustrator ${ }^{\circledR}$ y Abobe Photoshop ${ }^{\circledR}$. La clave dicotómica para obreras y soldados se elaboró con base en la información previamente publicada por Watkins $(1982,1988)$, así como Snelling y Snelling (2007). En la clave dicotómica, se omitieron cinco especies que son solo conocidas a partir de los machos. 

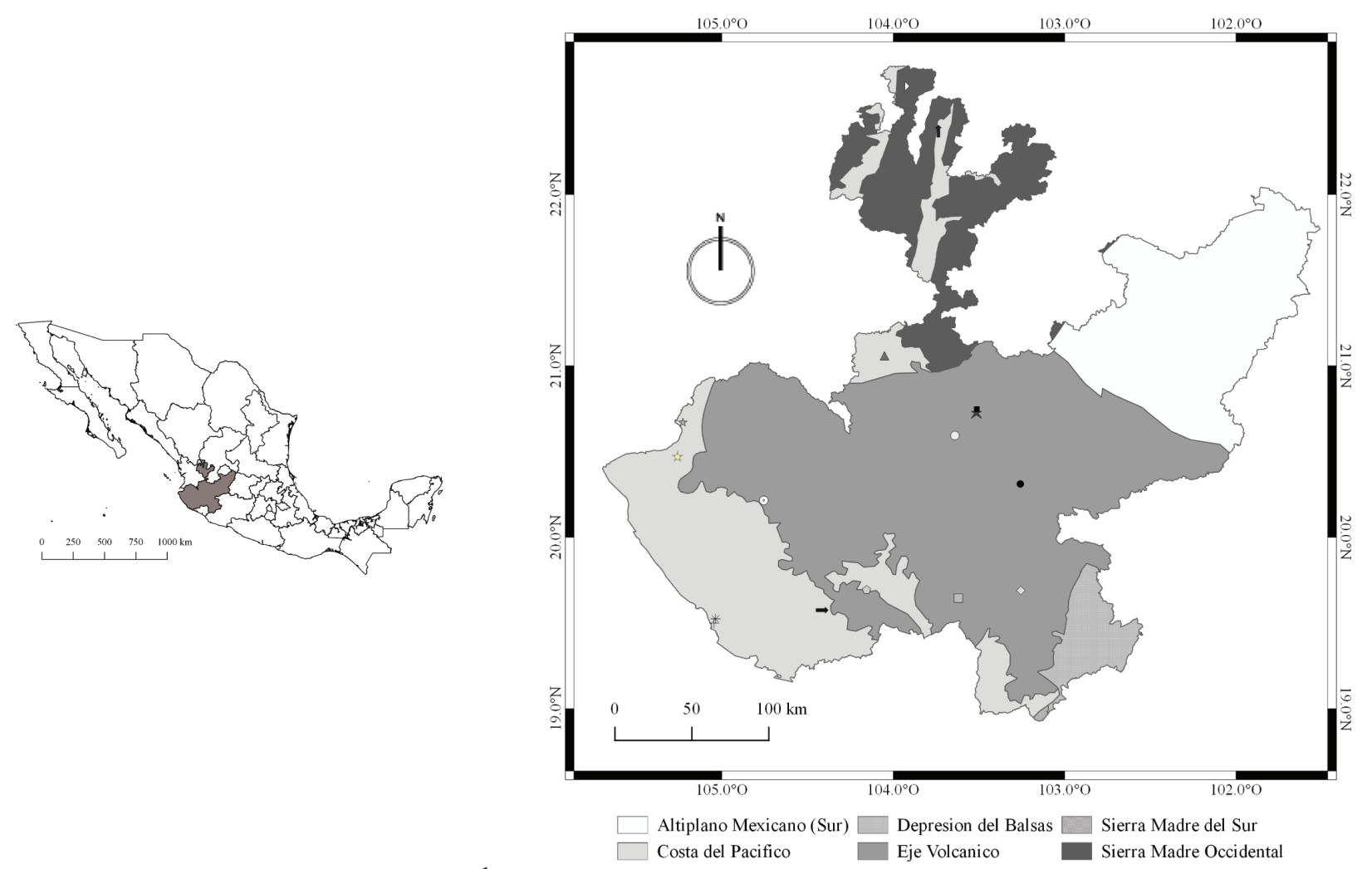

$1 \mathbf{a}$
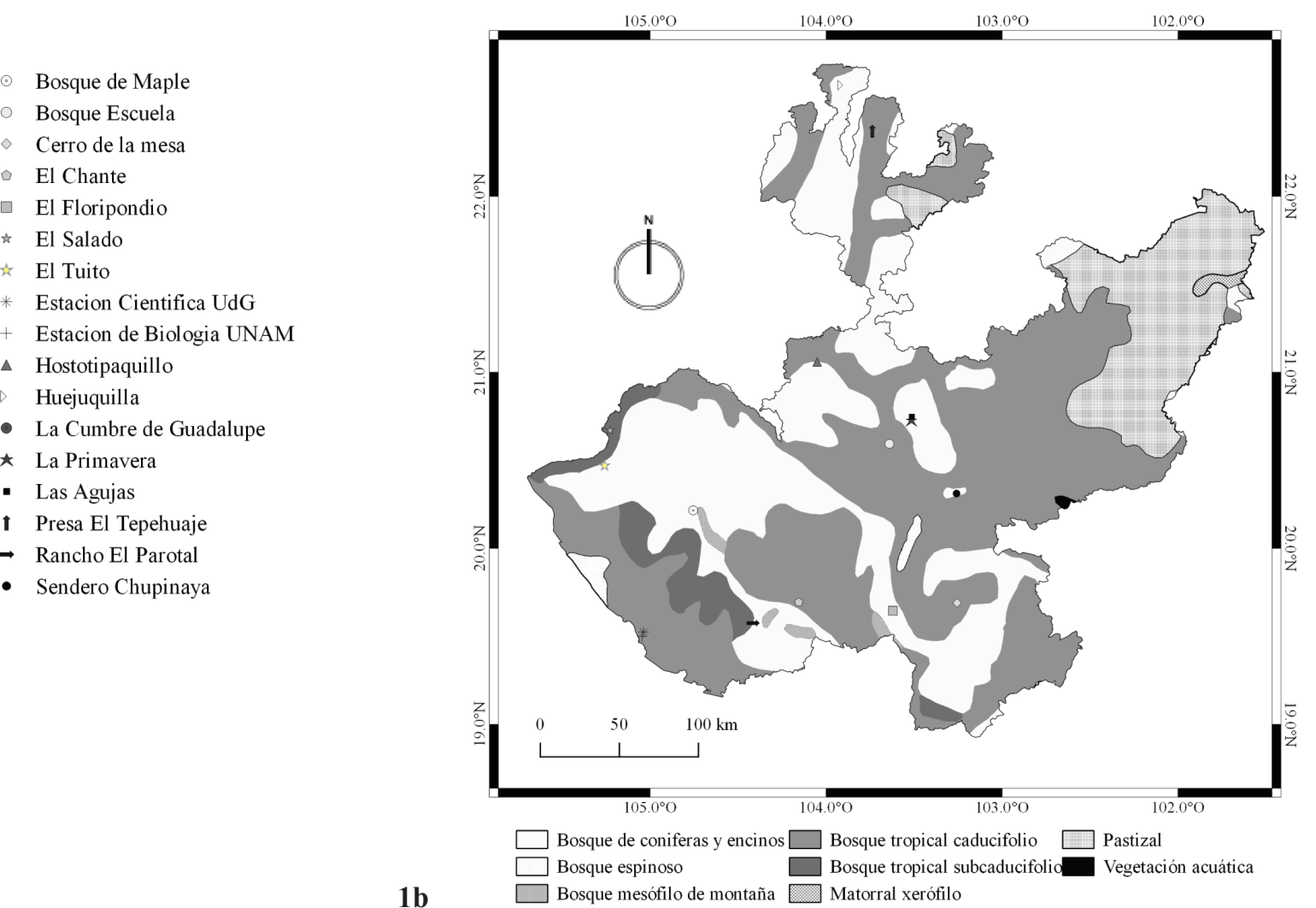

Figura 1. a) Provincias biogeográficas de Jalisco y localidades muestreadas (julio 2014-noviembre 2015) (Morrone 2005; CONABIO 2008a; Morrone and Márquez 2008). b) Tipos de vegetación de Jalisco y localidades muestreadas (jululio 2014-noviembre 2015) (Rzedowski 2006; CONABIO 2008b). 


\section{RESULTADOS}

Se revisaron 21,167 ejemplares de hormigas legionarias procedentes de 107 localidades en 51 municipios de Jalisco; 19,784 depositados en la colección CZUG (16,961 previamente depositados y 2,823 colectados en el presente estudio), 756 en EEBC, 548 en LESMA y 79 en CNIN. Se agruparon en cuatro géneros con 24 especies y dos morfoespecies. Neivamyrmex registró la mayor riqueza con 19 especies y una morfoespecie. Para Eciton se tuvieron tres especies y una morfoespecie; mientras que para Labidus y Nomamyrmex una especie cada uno (Cuadro 1). Tres especies se registraron por primera vez para Jalisco: Neivamyrmex halidaii (Shuckard, 1840), N. impudens (Mann, 1922) y N. pauxillus (Wheeler, 1903). La clave incluye únicamente 20 especies y una morfoespecie del total registrado para el estado: 15 especies de Neivamyrmex, tres especies y una morfoespecie de Eciton, así como una especie para Labidus y Nomamyrmex, respectivamente (Cuadro 1).

\section{Lista comentada de las especies de hormigas legionarias de Jalisco}

\section{Dorylinae Leach, 1815 \\ Eciton Latreille, 1804}

Es el género más conspicuo de la subfamilia en el Nuevo Mundo. Los soldados son fácilmente reconocibles por sus largas mandíbulas en forma de anzuelo (Palacio 2003). La biología de las especies de Eciton es, posiblemente, la mejor conocida entre los miembros de la subfamilia; se tienen datos precisos acerca de la duración de sus fases estacionaria y nómada (Palacio 2003). Se conocen 29 especies, cuatro de las cuales se encuentran en México. Para Jalisco, se tiene el registro de tres especies (AntWeb 2016a; Vásquez-Bolaños 2011; Vásquez-Bolaños 2015).

\section{Eciton burchellii parvispinum Forel, 1899}

\section{(Fig. 2)}

Diagnosis: hormigas de tamaño grande. Longitud de 10 a $20 \mathrm{~mm}$. Los soldados presentan coloración amarilla opaca en la cabeza, mesosoma y peciolo. Pospeciolo, gáster y apéndices con coloración castaña oscura. Mandíbulas prolongadas, con longitud mayor a los $3 \mathrm{~mm}$, en forma de gancho, presentan una ligera constricción hacia su región distal (Fig. 2c). Cabeza con proyecciones posterolaterales ligeramente desarrolladas, a manera de pequeños dientecillos (Figs. 2a y 2b). Propodeo en vista lateral con presencia de dientes triangulares poco elevados, separados, no conectados por una carina al observarlos en vista dorsal-oblicua (Figs. 2b y 2d). Las obreras varían en tamaño, algunas son tan grandes como los soldados, otras con una longitud aproximada de $10 \mathrm{~mm}$ o más pequeñas, la coloración del cuerpo, cabeza, mesosoma, gáster y apéndices es por lo general la misma: castaño-oscuro (Watkins 1982).

Distribución en México: Chiapas, Colima, Guerrero,
Cuadro 1. Lista de especies de hormigas legionarias (Dorylinae) presentes en Jalisco y sus castas conocidas (R: reina, M: macho, S-O: soldado u obrera). *Primeros registros para Jalisco.

+Incluidas en la clave.

Especie

Eciton burchellii parvispinum Forel, $1899+$

Eciton mexicanum Roger, 1863+

Eciton vagans angustatum Roger, 1863+

Eciton sp.+

Labidus coecus (Latreille, 1802)+

Neivamyrmex agilis Borgmeier, 1953+

Neivamyrmex andrei (Emery, 1901) Castas conocidas

Neivamyrmex chamelensis Watkins 1986+

Neivamyrmex cornutus Watkins, 1975+

Neivamyrmex fuscipennis (Smith, 1942) R M S-O

Neivamyrmex graciellae (Mann, 1926)+

Neivamyrmex halidaii (Shuckard, 1840)*

Neivamyrmex harrisii (Haldeman, 1852)+

Neivamyrmex impudens (Mann, 1922)*+

Neivamyrmex mandibularis (Smith, 1942)

Neivamyrmex melanocephalus (Emery, $1895)+$

Neivamyrmex nigrescens (Cresson, 1872)+ $\mathrm{x} \quad \mathrm{x} \quad \mathrm{x}$

Neivamyrmex opacithorax (Emery, 1894)+ x $\quad \mathrm{x} \quad \mathrm{x}$

Neivamyrmex pauxillus (Wheeler, 1903)*+ ${ }^{*} \quad$ x

Neivamyrmex pilosus (Smith, 1858)+ $\quad$ x $\quad$ x $\quad$ x

Neivamyrmex rugulosus Borgmeier, 1953+ $\quad \mathrm{x}$

Neivamyrmex sumichrasti (Norton, 1868)+ $\quad$ X $\quad \mathrm{x}$

Neivamyrmex swainsonii (Shuckard, $\quad$ x $\quad \mathrm{x}$ 1840)+

Neivamyrmex texanus (Watkins 1972)+ $\quad$ x $\quad$ x $\quad$ x

Neivamyrmex sp.

Nomamyrmex esenbeckii (Westwood, 1842)+

Hidalgo, Jalisco, Oaxaca, Puebla, Querétaro, Quintana Roo, San Luis Potosí, Sinaloa, Tabasco, Tamaulipas, Veracruz y Yucatán (Vásquez-Bolaños 2015).

Comentarios: es una de las especies de hormigas legionarias más colectadas. Sus batidas de cacería son amplias y muy difíciles de ignorar (Lattke et al. 2007). Durante el trabajo de campo, en la localidad de El Chante, municipio de Autlán de Navarro, se observaron batidas de cacería de una colonia de E. burchelli parvispinum trepando sobre un árbol a la par que batidas de E. vagans angustatum. Ambas subespecies se toparon en el camino 
en varias ocasiones, pero se ignoraron. Se observaron en ataque de un nido de Camponotus sp. Se contabilizaron 7,254 individuos.

\section{Eciton mexicanum Roger, 1863}

(Fig. 3)

Diagnosis: hormigas de tamaño grande, las obreras alcanzan un tamaño de 8 a $18 \mathrm{~mm}$, los soldados entre los 18 y $20 \mathrm{~mm}$ de longitud. Cuerpo con coloración castaño rojizo en la cabeza, mesosoma, peciolo y pospeciolo, misma que se aprecia con menor intensidad en el gáster y los apéndices. Mandíbulas oscuras, no tan prolongadas, longitud igual o menor a los $3 \mathrm{~mm}$, en forma de gancho, con presencia de un pequeño dientecillo en la región media proximal (Fig. 3a). Cabeza con proyecciones desarrolladas posterolateralmente, a manera de pequeños cuernos (Figs. 3a, d). Mesosoma en vista lateral con la presencia de espinas propodeales (Fig. 3b), las que se encuentran fusionadas o conectadas por una carina al observarlas en vista dorsal-oblicua (Fig. 3d). Pilosidad del cuerpo abundante, caracterizada por la presencia de sedas erectas y semierectas en apéndices, cabeza, mesosoma, peciolo, pospeciolo y gáster (Figs. 3a, b). Las obreras presentan el mismo patrón de coloración que los soldados (Watkins 1982).

Distribución en México: Chiapas, Colima, Hidalgo, Jalisco, Oaxaca, San Luis Potosí, Tabasco, Tamaulipas y Veracruz (Vásquez-Bolaños 2011, 2015).

Comentarios: las batidas de caza son menores a las observadas en otras especies del género. Usualmente son más activas de noche y suelen ser algo tímidas, ya que detienen su columna de cacería al ser perturbadas y se ocultan en la vegetación (Lattke et al. 2007). Se observaron 71 individuos. El método de captura más frecuente fue colecta directa, seguido por el uso de necrotrampas.

\section{Eciton vagans angustatum Roger, 1863}

\section{(Fig. 4)}

Diagnosis: hormigas de tamaño grande, las obreras alcanzan un tamaño de 10 a $20 \mathrm{~mm}$, los soldados $20 \mathrm{~mm}$ de longitud o más. Cuerpo con coloración castaño rojizo en cabeza, mesosoma, misma que se aprecia con menor intensidad en el peciolo, pospeciolo, gáster y apéndices. Mandíbulas oscuras, prolongadas, con longitud mayor a los $3 \mathrm{~mm}$, en forma de gancho. Cabeza con proyecciones dorsolaterales ligeramente desarrolladas a manera de dientes triangulares (Figs. 4a, d). Mesosoma en vista lateral con presencia de espinas propodeales (Fig. 4b), las que se encuentran separadas, nunca fusionadas o unidas por una carina en vista dorsal-oblicua (Fig. 4d). Pilosidad del cuerpo abundante, caracterizada por la presencia de sedas erectas y semierectas en apéndices, cabeza, mesosoma, peciolo, pospeciolo y gáster (Figs. 4a, b). Las obreras presentan un patrón de coloración castaño oscuro o rojizo en comparación con los soldados, algunas alcanzan la misma longitud (Figs. 4a, b) (Watkins 1982).

Distribución en México: Chiapas, Jalisco, Nuevo León,
Oaxaca, Querétaro, San Luis Potosí, Veracruz y Yucatán (Vásquez-Bolaños 2011,2015).

Comentarios: presenta batidas de cacería tan amplias que al encontrarlas en el campo pueden confundirse con las de E. burchelli parvispinum. En la localidad de El Chante, municipio de Autlán, se observaron columnas de ambas especies marchando juntas y atacaban un nido de Camponotus sp. Al observar a los soldados, fue fácil distinguir a $E$. vagans angustatum por su coloración rojiza y dientes propodeales espiniformes. Se observaron 679 individuos. El método de captura más frecuente para la obtención de ejemplares fue la colecta directa, seguido del uso de necrotrampas.

\section{Eciton sp. \\ (Fig. 5)}

Diagnosis: hormigas de tamaño grande, los soldados alcanzan los $20 \mathrm{~mm}$ de longitud. Cuerpo alargado. Mandíbulas de los soldados en forma de gancho, con un ligero adelgazamiento en la base y un fuerte engrosamiento hacia la región media de las mismas (Fig. 5c). Procesos propodeales poco elevados, en forma de dientes con el ápice redondeado en vista dorsal-oblicua (Fig. 5d). Pilosidad del cuerpo abundante, caracterizada por la presencia de sedas erectas y semierectas en apéndices, cabeza, mesosoma, peciolo, postpeciolo y gáster (Figs. 5a, b). Peciolo en forma semicircular a ovoidal en vista dorsal (Fig. 5a). Soldados con coloración castaño oscuro en cabeza, mesosoma y peciolo; pospeciolo, gáster y apéndices presentan color oscuro. Obreras de color café oscuro a negro (Watkins 1982).

Distribución en México: Jalisco.

Comentarios: se observó en su etapa estacionaria (vivac) mientras anidaba en un tronco, en un área de bosque mesófílo de montaña semiperturbada cercana al Nevado de Colima. Los patrones de color que presenta son distintos a los observados en los soldados de otras especies del género. Además, tiene una combinación de caracteres morfológicos que sugieren que podría tratarse de una especie nueva para la ciencia. Se observaron 75 individuos. El método de captura utilizado para la obtención de ejemplares fue colecta directa.

\section{Labidus Jurine, 1807}

Después de Eciton, es el género más sobresaliente de la subfamilia en el Nuevo Mundo por su amplia distribución y lo numerosas de sus colonias. Son dominantes en regiones medias y altas, donde el efecto que ejercen en la población de invertebrados y pequeños vertebrados es considerable (Palacio 2003). Los soldados son fácilmente reconocibles por presentar cabezas muy grandes en relación con el resto del cuerpo y ojos bastante reducidos (Watkins 1982). Labidus cuenta con nueve especies, de las que dos están ampliamente distribuidas en México y solo una en Jalisco (AntWeb 2016a; Vásquez-Bolaños 2011, 2015). 


\section{Labidus coecus (Latreille, 1802)}

(Fig. 6)

Diagnosis: hormigas de tamaño mediano. Longitud de las obreras $5 \mathrm{~mm}$ y, en el caso de los soldados, alcanzan o superan los $12 \mathrm{~mm}$. Cuerpo con cutícula lisa y brillante. Soldados caracterizados por poseer cabezas de tamaño muy grande, de al menos una tercera parte de la longitud total del cuerpo (Fig. 6a), y mandíbulas con dientes agudos. Dorso del propodeo liso, redondeado, sin la presencia de espinas o proyecciones (Figs. 6b, c). Peciolo en vista lateral, con presencia de diente anteroventral triangular y agudo (Fig. 6b). Superficie cóncava de las uñas tarsales con un diente. Pilosidad del cuerpo caracterizada por presentar sedas erectas y semierectas en apéndices, cabeza, mesosoma, peciolo, pospeciolo y gáster (Figs. 6a, b). Hormigas de color castaño rojizo (Watkins 1982).

Distribución en México: Aguascalientes, Campeche, Chiapas, Chihuahua, Ciudad de México, Coahuila, Guanajuato, Guerrero, Hidalgo, Jalisco, Estado de México, Michoacán, Morelos, Nayarit, Nuevo León, Oaxaca, Puebla, Querétaro, Quintana Roo, San Luis Potosí, Sinaloa, Tabasco, Tamaulipas, Tlaxcala, Veracruz, Yucatán y Zacatecas (Vásquez-Bolaños 2015).

Comentarios: las obreras de L. coecus pueden confundirse con obreras de algunas especies del género Neivamyrmex; situación que se puede dirimir al observar la ornamentación interna de las uñas tarsales con la presencia de un diente.

Es la especie con el mayor intervalo de distribución en el Nuevo Mundo, desde el este y sureste de los Estados Unidos de América, hasta el norte de Argentina (Wetterer y Snelling 2015). Se ha registrado en una gama de gradientes altitudinales, en los trópicos y subtrópicos de Norte y Sudamérica y en una amplia variedad de tipos de vegetación (Longino 2016); además, aunque en el campo se pueden observar columnas epigeas de la especie, es más frecuente encontrarlas por debajo del suelo o en cuevas. Probablemente, la estabilidad de las condiciones climáticas que ofrecen este tipo de hábitats, le ha permitido extender su distribución en diversos ambientes que podrían parecer poco favorables (Wetterer y Snelling 2015). Su dieta incluye artrópodos, anélidos (Palacio 2003; Lattke et al. 2007), carroña, pequeños mamíferos y anfibios. En el campo se observaron soldados atacando a un ejemplar adulto de la salamandra Isthmura bellii. Además, está asociada con la dispersión de semillas que contienen eleosomas, que usa como fuente de alimento (Rico-Gray y Oliveira 2007). Se registraron 8,991 ejemplares. El método de captura más frecuente para la obtención de ejemplares fueron las necrotrampas y trampas subterráneas; además de colecta directa, tanto para soldados como para obreras.

\section{Neivamyrmex Borgmeier, 1940}

Es el género más diverso de la subfamilia Dorylinae en el Nuevo Mundo (AntWeb 2016a). Cuenta con 129 especies distribuidas en la región Neotropical y parte de la región Neártica; con registros en las zonas áridas del país y Estados Unidos de América (Snelling y Snelling 2007; AntWeb 2015; Vásquez-Bolaños 2015). Se distingue por la ausencia de dientecillos en las uñas tarsales, característica que debe observarse con detalle, ya que frecuentemente son confundidas con obreras menores de Eciton, Labidus o Nomamyrmex (Palacio 2003). Para México, VásquezBolaños (2015) enlista 43 especies. Algunos autores como Palacio (2003), Lattke et al. (2007) y Snelling y Snelling (2007), mencionan que el género requiere de una revisión taxonómica.

\section{Neivamyrmex agilis Borgmeier, 1953}

(Fig. 7)

Diagnosis: hormigas de tamaño pequeño. Longitud de $5 \mathrm{~mm}$. Cuerpo en su mayoría con cutícula lisa y brillante, con presencia de rugosidades en el dorso y costados del mesosoma (Figs. 7a, b). Ojos muy reducidos, representados por una mancha debajo de la cutícula. Sutura entre el promesonoto y la mesopleura completa en vista lateral (Figs. 7a, d). Pilosidad del cuerpo caracterizada por la presencia de sedas erectas y semierectas en apéndices, cabeza, mesosoma, peciolo, pospeciolo y gáster (Figs. 7a, b). Hormigas de color castaño rojizo (Watkins 1982).

Distribución en México: Chihuahua, Morelos, Jalisco, Sonora y Veracruz (Vásquez-Bolaños 2015).

Comentarios: existen pocos datos acerca de la biología de esta especie. Aunque las castas reproductoras no han sido descritas, Snelling y Snelling (2007) sugieren que existe evidencia de que $N$. andrei representa la casta de machos de $N$. agilis. Se revisaron 253 ejemplares. Los métodos de captura más frecuente para la obtención de ejemplares fueron las trampas NTP-80 y de caída, complementado con colecta directa.

\section{Neivamyrmex chamelensis Watkins, 1986}

(Fig. 8)

Diagnosis: hormigas de tamaño pequeño. Longitud de 4 $\mathrm{mm}$. Cabeza con escultura lisa y brillante. Ojos presentes, representados por un omatidio. Carinas interrumpidas justo al frente de las inserciones antenales (Fig. 8c). Dorso del propodeo liso, sin la presencia de espinas o dientes (Figs. $8 b)$. Pospeciolo alargado en vista dorsal, casi de la misma longitud que el peciolo (Figs. 8a, d). Peciolo en vista lateral sin la presencia de un diente anteroventral diferenciado (Fig. $8 b)$. Hormigas de color castaño rojizo fuerte en mesosoma; cabeza, peciolo, pospeciolo y gáster de color castaño claro; apéndices de color castaño-amarillento (Watkins 1982).

Distribución en México: Jalisco (Vásquez-Bolaños 2015).

Comentarios: solo se conoce para la localidad tipo, ubicada en la Estación de Biología Chamela, UNAM, municipio de La Huerta, Jalisco. Tanto la casta obrera como la reina fueron descritas. Se observaron dos ejemplares recolectados con trampa malaise. 


\section{Neivamyrmex cornutus Watkins, 1975}

(Fig. 9)

Diagnosis: la longitud de los soldados alcanza los 5 mm. Cabeza con escultura granulosa. Ojos presentes, representados por un omatidio. Porción cóncava del margen posterior de la cabeza más amplia que el ancho máximo del mesosoma en vista dorsal (Fig. 9a). Esquinas posterolaterales de la cabeza proyectándose fuertemente en vista dorsal y vista frontal, a manera de cuernos (Figs. 9a, c). Superficie dorsal del propodeo más larga que la superficie descendente en vista lateral (Fig. 9b). Pilosidad del cuerpo caracterizada por la presencia de sedas erectas y semierectas (Figs. 9a, b). Hormigas de color castaño oscuro en cabeza, mesosoma y apéndices, gáster de color castaño rojizo (Watkins 1982).

Distribución en México: Ciudad de México, Jalisco, Morelos, Oaxaca, Puebla y Sonora (Vásquez-Bolaños 2015).

Comentarios: solo se han descrito las castas de obreras y soldados. Son fácilmente reconocibles del resto de las especies del género por las proyecciones que presentan en las esquinas posteriores de la cabeza, a manera de cuernos (Watkins 1982). Se observó formando grandes batidas de cacería que emergían del suelo. Al ser perturbadas, detenían su actividad y se escondían entre la hojarasca o debajo de las piedras. Se observaron 505 ejemplares. El método de captura más frecuente fue la colecta directa, ocasionalmente necrotrampas y trampas tipo pitfall.

\section{Neivamyrmex graciellae (Mann, 1926)}

(Fig. 10)

Diagnosis: hormigas de 2 a $4 \mathrm{~mm}$ de longitud. Cabeza con escultura lisa y brillante. Ojos presentes, representados por un omatidio. Córnea convexa presente. Porción cóncava del margen posterior de la cabeza más angosta que el ancho máximo del mesosoma en vista dorsal (Fig. 10a). Proceso anteroventral del peciolo largo y triangular, con el ápice dirigido posteroventralmente (Fig. 10d). Lamelas anteriores a las inserciones antenales estrechas o ausentes (Fig. 10c). Hormigas de color castaño rojizo, donde el gáster es más oscuro (Watkins 1982).

Distribución en México: Jalisco, Morelos, Oaxaca y Veracruz (Vásquez-Bolaños 2015).

Comentarios: solo se conocen las castas reina y obrera. A simple vista, las obreras pueden confundirse con obreras de $N$. impudens, pero se diferencian de ellas porque ostentan un proceso subpeciolar triangular y con el ápice dirigido posteroventralmente. Snelling y Snelling (2007), mencionan que existe la posibilidad de que $N$. graciellae corresponda a la casta obrera de $N$. mandibularis (que solo ha sido descrita en machos). Esta situación se resolverá hasta que se realice la revisión taxonómica del grupo.

Existen pocos datos sobre la biología de $N$. graciellae. En campo se colectó con mayor frecuencia en bosques tropicales. Por lo general, se observaban batidas de cacería poco numerosas, quizá debido a que la mayor parte de la actividad de sus colonias se realiza por debajo del suelo. Se observaron 505 ejemplares. El método de captura más frecuente fue la colecta directa y ocasionalmente necrotrampas.

\section{Neivamyrmex harrisii (Haldeman, 1852)}

(Fig. 11)

Diagnosis: hormigas de 3 a $4 \mathrm{~mm}$ de longitud. Cabeza con escultura lisa y brillante. Ojos presentes, representados por un omatidio. Carinas frontales curveadas anteriores a las inserciones antenales, formando una lamela que se estrecha lateralmente de manera gradual (Fig. 11c). Porción cóncava del margen posterior de la cabeza más amplia que el ancho máximo del mesosoma en vista dorsal (Fig. 11a). Esquinas posterolaterales de la cabeza proyectándose en vista dorsal a manera de dientecillos (Figs. 11a, c). Peciolo con forma semicuadrada en vista dorsal (Fig. 11d). Superficies dorsales y laterales del peciolo y pospeciolo rugosas o granulosas. Pilosidad del cuerpo caracterizada por la presencia de sedas erectas y semierectas (Figs. 11a, b). Hormigas de color castaño rojizo en cabeza, mesosoma, peciolo y pospeciolo, así como color castaño amarillento en el gáster y apéndices (Watkins 1982).

Distribución en México: Aguascalientes, Chihuahua, Coahuila, Colima, Durango, Hidalgo, Jalisco, Nayarit, Nuevo León, San Luis Potosí, Sinaloa, Sonora, Tamaulipas y Zacatecas (Vásquez-Bolaños 2015).

Comentarios: han sido descritas tanto las castas reproductoras (reina y macho) como las obreras; incluso, Watkins (1968) describió los estadios inmaduros (larva y pupa) de los machos.

Las obreras son fácilmente reconocibles por la forma semicuadrada del peciolo en vista dorsal. Los machos son regularmente colectados en campo con trampas de luz o por el alumbrado público en zonas semiurbanas. Se observaron 122 individuos. El método de captura más frecuente fue colecta directa y trampas de luz para los machos y ocasionalmente necrotrampas para obreras.

\section{Neivamyrmex impudens (Mann, 1922)}

(Fig. 12)

Diagnosis: hormigas de 3 a $6 \mathrm{~mm}$ de longitud. Cabeza con escultura lisa y brillante. Ojos presentes, representados por un omatidio. Córnea convexa presente. Porción cóncava del margen posterior de la cabeza más angosta que el ancho máximo del mesosoma en vista dorsal (Fig. 12a). Proceso anteroventral del peciolo espinoso, con el ápice dirigido ventralmente (Fig. 12d). Lamelas al frente de las inserciones antenales presentes y amplias (Fig. 12c). Hormigas de color castaño amarillento o castaño rojizo-claro (Watkins 1982).

Distribución en México: Chiapas, Morelos, San Luis Potosí y Yucatán (Vásquez-Bolaños 2015).

Comentarios: solo se ha descrito la casta de obreras, que se distinguen de $N$. graciellae por el color castaño amarillento de la cabeza, mesosoma y gáster, así como por presentar un proceso subpeciolar agudo y dirigido 
ventralmente. Se conoce muy poco sobre su biología. Se observaron 15 individuos, todos capturados por colecta directa. Este es el primer registro de la especie para Jalisco.

\section{Neivamyrmex melanocephalus (Emery, 1895)}

(Fig. 13)

Diagnosis: hormigas de 3 a $4.5 \mathrm{~mm}$ de longitud. Cabeza con escultura lisa y brillante. Ojos presentes, representados por un omatidio. Carinas frontales estrechas al frente de las inserciones antenales (Fig. 13c). Porción cóncava del margen posterior de la cabeza más angosta que el ancho máximo del mesosoma en vista dorsal (Fig. 13a). Peciolo con forma semirectangular en vista dorsal (Fig. 13a). Proceso anteroventral del peciolo muy pequeño, dirigido ventralmente (Fig. 13d). Es fácil de distinguir del resto de las especies del género por su patrón de coloración característico: cabeza y gáster negro, mesosoma y apéndices castaño-rojizo (Watkins 1982).

Distribución en México: Durango, Hidalgo, Jalisco, Michoacán, Morelos, Nayarit, Nuevo León, Oaxaca, San Luis Potosí y Sonora (Vásquez-Bolaños 2015).

Comentarios: se observó en diversas ocasiones durante los meses de diciembre de 2014 y enero de 2015 forrajeando en distintos puntos de una misma localidad (campus del Centro Universitario de Ciencias Biológicas y Agropecuarias, Las Agujas, Zapopan), posiblemente porque la colonia se encontraba en su fase estacionaria. Presentó columnas de cacería numerosas. Entre sus presas se incluyeron a otros insectos, principalmente dermápteros y blatodeos, e incluso otras hormigas (Crematogaster sp.). Siempre se encontró emergiendo de los ductos de drenaje del campus universitario, por lo que se especula que sus hábitos son principalmente hipogeos. Solo se han descrito obreras y soldados. Durante el proceso de revisión del material depositado en la colección del CZUG, se encontraron dos machos; desafortunadamente, el alcohol se evaporó y los ejemplares se deterioraron en el proceso de rehidratación y no se revisaron. Los soldados son de tamaño considerable, por lo que pueden ser confundidos con obreras menores del género Eciton. La revisión de la ornamentación del propodeo es de ayudará en su determinación. Se observaron 1,684 individuos. El método de captura más frecuente fue colecta directa, seguida por necrotrampas y pitfall.

\section{Neivamyrmex nigrescens (Cresson, 1872)}

(Fig. 14)

Diagnosis: hormigas con longitud de $4 \mathrm{~mm}$. Cabeza y mesosoma con escultura rugosa. Ojos presentes, representados por un omatidio. Ángulos posterolaterales de la cabeza proyectándose moderadamente, con la presencia de pequeños dientecillos (Fig. 14a). Unión de las superficies dorsal y descendente del propodeo redondeada, nunca formando un ángulo (Fig. 14d). Peciolo más largo que alto en vista lateral (Figs. 14b, d). Hormigas de color castaño rojizo (Watkins 1982).
Distribución en México: Baja California, Baja California Sur, Chiapas, Guerrero, Hidalgo, Jalisco, Morelos, Nayarit, Oaxaca, Puebla, San Luis Potosí, Sonora, Tamaulipas, Veracruz y Yucatán (Vásquez-Bolaños 2015).

Comentarios: se distingue de $N$. texanus por ser más pequeña y por la forma de la unión de las superficies dorsal y descendente del propodeo redondeado. Es la especie con mayor amplitud de distribución en la región Neártica (principalmente en los Estados Unidos de América). Sus colonias son numerosas, desde 150,000 a 250,000 obreras. Cuando se encuentran en su fase estacionaria, por lo general anidan en huecos en el suelo o en las cavidades de los nidos de otras hormigas que saquean (Snelling y Snelling 2007). Se observaron 125 individuos. El método de captura más frecuente fue colecta directa, seguida por necrotrampas.

\section{Neivamyrmex opacithorax (Emery, 1894)}

(Fig. 15)

Diagnosis: hormigas con longitud de 2.5 a $3.5 \mathrm{~mm}$. Cabeza con escultura lisa y brillante, con puntuaciones dispersas. Ojos presentes, representados por un omatidio. Porción cóncava del margen posterior de la cabeza más amplia que el ancho máximo del mesosoma en vista dorsal (Fig. 15a). Pospeciolo poco desarrollado en vista dorsal, de menor longitud que el peciolo (Figs. 15a, d). Peciolo en vista lateral sin la presencia de un diente anteroventral diferenciado (Fig. 15b). Hormigas de color castaño rojizo en cabeza, mesosoma, peciolo y pospeciolo, gáster y apéndices de color castaño amarillento (Watkins 1982).

Distribución en México: Baja California, Baja California Sur, Hidalgo, Jalisco, Morelos, Oaxaca, Sonora, Tabasco, Tamaulipas y Veracruz (Vásquez-Bolaños 2015).

Comentarios: es una especie ampliamente distribuida, aunque sus colectadas son infrecuentes. Son consideradas depredadoras de otras hormigas (Snelling y Snelling 2007). Se observaron 172 especímenes. El método de captura más frecuente fue colecta directa, seguida por necrotrampas y trampas pitfall.

\section{Neivamyrmex pauxillus (Wheeler, 1903)}

(Fig. 16)

Diagnosis: es una de las especies más pequeñas del género. Longitud de 1.5 a $2 \mathrm{~mm}$ (Fig. 16a). Cuerpo con cutícula lisa y brillante. Ojos ausentes. Escapo antenal corto, su longitud no alcanza la mitad de la cabeza en vista frontal (Fig. 16c) Sutura entre el promesonoto y la mesopleura incompleta en vista lateral (Figs. 16b, d). Superficie dorsal del propodeo distintivamente mayor que la superficie descendente en vista lateral (Fig. 16d). Hormigas de color castaño amarillento (Watkins 1982).

Distribución en México: Hidalgo, Morelos, Tamaulipas y Veracruz (Vásquez-Bolaños 2015).

Comentarios: debido a que son colectadas raramente, se conoce poco sobre sus hábitos. Se cree que son depredadoras de termitas y de otras hormigas (Snelling y Snelling 2007). Se observaron nueve especímenes. El método de captura 
más frecuente fue el de trampas pitfall, seguido por trampas malaise. Primer registro para Jalisco.

\section{Neivamyrmex pilosus (Smith, 1858)}

(Fig. 17)

Diagnosis: hormigas de 3 a $4.5 \mathrm{~mm}$ de longitud. Cabeza con escultura lisa y brillante. Ojos presentes, representados por un omatidio. Porción cóncava del margen posterior de la cabeza más angosta que el ancho máximo del mesosoma en vista dorsal. Peciolo con forma semirectangular en vista dorsal (Fig. 17a). Proceso anteroventral del peciolo prominente y agudo, en forma de una espina dirigida posteroventralmente (Figs. 17b, d). Hormigas de color castaño oscuro (Watkins 1982).

Distribución en México: Chiapas, Colima, Durango, Jalisco, Nayarit, Oaxaca, San Luis Potosí, Sinaloa y Veracruz (Vásquez-Bolaños 2015).

Comentarios: los soldados y obreras son muy parecidos a los de N. melanocephalus. Es fácil diferenciarlos, ya que el patrón de coloración es castaño oscuro en todo el cuerpo y el proceso ventral del peciolo suele ser muy desarrollado y fácil de distinguir al observarlas al microscopio. Lattke et al. (2007), mencionan que al ser encontrada en campo, despide un fuerte olor fecal que puede impregnar hasta al alcohol. Sus columnas de cacería por lo general usan atajos por encima del suelo, como ramas caídas, bejucos u otros objetos que sirven de puentes para evitar andar entre las irregularidades de la hojarasca. Se observaron cuatro especímenes. El método de captura más frecuente fue la colecta directa y trampas de luz.

\section{Neivamyrmex rugulosus Borgmeier, 1953}

(Fig. 18)

Diagnosis: hormigas con longitud de 4 a $5 \mathrm{~mm}$. Cabeza y mesosoma con escultura rugosa a granulosa. Ojos presentes, representados por un omatidio. Porción cóncava del margen posterior de la cabeza más amplia que el ancho máximo del mesosoma en vista dorsal (Fig. 18a). Ángulos posterolaterales de la cabeza proyectándose ligeramente, pero sin la presencia de cuernos o dientes (Fig. 18a). Es fácil distinguirla del resto de las especies del género, ya que al observarla bajo el microscopio estereoscópico, se aprecia que de la superficie interna de la mandíbula forma un ángulo casi recto en su unión con la superficie masticadora (Figs. $18 \mathrm{c}, \mathrm{d})$. Hormigas de color castaño rojizo oscuro en cabeza, mesosoma, peciolo y pospeciolo, gáster y apéndices de color castaño rojizo (Watkins 1982).

Distribución en México: Jalisco, Nayarit, Sonora y Veracruz (Vásquez-Bolaños 2015).

Comentarios: es una de las especies menos conocidas del género. Poco se sabe sobre su biología; ocasionalmente ha sido observada depredando a otras hormigas de los géneros Trachymyrmex y Pheidole (Snelling y Snelling 2007). Se observaron 79 especímenes. El método de captura más frecuente fue la colecta directa.

\section{Neivamyrmex sumichrasti (Norton, 1868)}

(Fig. 19)

Diagnosis: hormigas con longitud de 3.5 a $4.5 \mathrm{~mm}$. Se distingue por el patrón de depresiones profundas, presentes en la cabeza y el mesosoma a manera de pequeños pozos, que es único entre las especies del género (Fig. 19c). Ojos presentes, representados por un omatidio. Porción cóncava del margen posterior de la cabeza más amplia que el ancho máximo del mesosoma en vista dorsal (Fig. 19a). Esquinas posterolaterales de la cabeza proyectándose fuertemente en vista dorsal y vista frontal (Fig. 19c). Pilosidad del cuerpo caracterizada por la presencia de sedas erectas y semierectas. Hormigas de color castaño oscuro o negro, gáster ocasionalmente de color castaño rojizo (Watkins 1982).

Distribución en México: Chiapas, Hidalgo, Jalisco, Michoacán, San Luis Potosí, Veracruz y Yucatán (VásquezBolaños 2015).

Comentarios: poco se conoce sobre la biología de esta especie (Watkins 1982). Se observaron 18 especímenes.

\section{Neivamyrmex swainsonii (Shuckard, 1840)}

(Fig. 20)

Diagnosis: hormigas con longitud de 4 a $4.5 \mathrm{~mm}$., cuerpo con cutícula lisa y brillante, con numerosas puntuaciones dispersas. Ojos muy reducidos, representados por un punto ubicado por debajo de la cutícula (Figs. 20a, b). Sutura entre el promesonoto y la mesopleura incompleta en vista lateral (Fig. 20d). Superficie dorsal del propodeo distintivamente menor que la superficie descendente en vista lateral (Fig. 20d). Hormigas de color castaño rojizo a castaño amarillento (Watkins 1982).

Distribución en México: Baja California, Campeche, Chiapas, Chihuahua, Coahuila, Colima, Durango, Hidalgo, Jalisco, Michoacán, Morelos, Nuevo León, Oaxaca, Puebla, San Luis Potosí, Sinaloa, Sonora, Tabasco, Tamaulipas, Veracruz y Yucatán (Vásquez-Bolaños 2015).

Comentarios: es considerada una de las especies más conspicuas del género en Norteamérica por el gran tamaño de los machos y la abundancia de sus colonias. La especie solo se conocía por reproductores machos. Posteriormente, se concluyó que $N$. fallax era la casta obrera de $N$. swainsonii (Snelling y Snelling 2007). Se observaron 49 especímenes.

\section{Neivamyrmex texanus Watkins, 1972}

(Fig. 21)

Diagnosis: soldados hasta de $5 \mathrm{~mm}$. Cabeza y mesosoma con escultura rugosa. Ojos presentes, representados por un omatidio. Ángulos posterolaterales de la cabeza proyectándose moderadamente (Figs. 21a, c). Unión de las superficies dorsal y descendente del propodeo redondeada, formando un ángulo casi recto, ligeramente redondeado (Fig. 21d). Peciolo tan largo como alto en vista lateral (Figs. $21 \mathrm{~b}$, d). Peciolo y pospeciolo densamente granulados. Hormigas de color castaño oscuro en cabeza, mesosoma, 
peciolo y pospeciolo; gáster y apéndices de color castaño rojizo (Watkins 1982).

Distribución en México: Chihuahua, Coahuila, Hidalgo, Jalisco, San Luis Potosí y Sonora (Vásquez-Bolaños 2015).

Comentarios: es una de las especies más grandes y conspicuas del género. Sus batidas de cacería a menudo pueden observarse a la distancia. Se encuentra ampliamente distribuida y se ha observado asociada a diferentes tipos de hábitats (Snelling y Snelling 2007). Se observaron 564 individuos. El método de colecta más frecuente para su captura fue colecta directa, seguido de necrotrampas.

\section{Nomamyrmex Borgmeier, 1936}

Es uno de los géneros menos diversos de la subfamilia Dorylinae, ya que cuenta con solo cuatro especies descritas (Palacio 2003; AntWeb 2016a). Sin embargo, en cuanto a su tamaño, estas hormigas pueden ser tan grandes como los soldados de Eciton (Palacio 2003). Además, se caracterizan por poseer un aspecto robusto y una cutícula gruesa (Lattke et al. 2007). Son principalmente hipogeas, aunque ocasionalmente sus batidas de cacería se observan a nivel del suelo o incluso en estratos arbóreos. En cuanto a sus hábitos alimenticios, están especializadas en depredar insectos sociales como avispas o especies de hormigas con un alto nivel de organización en sus nidos, como las del género Atta (Lattke et al. 2007; Palacio 2003). Para México, se cuenta con registros de dos especies, una de las cuales se encuentra ampliamente distribuida y ocurre en Jalisco (Vásquez-Bolaños 2011).

\section{Nomamyrmex esenbeckii (Westwood, 1842)}

(Fig. 22)

Diagnosis: hormigas de tamaño grande. Longitud de 7 a $15 \mathrm{~mm}$. Cuerpo con cutícula gruesa y rugosa (Figs. 22a, b). Ojos presentes, representados por un omatidio. Escapo antenal corto y grueso, anchura del ápice mayor que un tercio de la longitud total del mismo (Fig. 22c). Propodeo caracterizado por la presencia de arrugas longitudinales prominentes, presentes en la mitad anterior del mismo. Superficie cóncava de las uñas tarsales con presencia de un diente (Fig., 22d). Pilosidad del cuerpo caracterizada por la presencia de sedas erectas y semierectas en apéndices, cabeza, mesosoma, peciolo, pospeciolo y gáster (Figs. 22a, b). Hormigas de color castaño rojizo (Watkins 1982).

Distribución en México: Chiapas, Ciudad de México, Chihuahua, Colima, Durango, Guerrero, Hidalgo, Jalisco, Estado de México, Michoacán, Morelos, Nayarit, Nuevo León, Oaxaca, Queretaro, Quintana Roo, San Luis Potosí, Sinaloa, Sonora, Tabasco, Tamaulipas, Veracruz y Yucatán (Vásquez-Bolaños 2015).

Comentarios: se han descrito las castas obrera y macho. Es fácil de distinguir del resto de las hormigas legionarias por su gran tamaño y la cutícula gruesa y rugosa que poseen soldados y obreras. Es el único depredador capaz de atacar con éxito un nido maduro de hormigas del género Atta. Además de su preferencia por atacar nidos de otras hormigas cultivadoras de hongos, como Trachymyrmex y Acromyrmex, también suelen elegir como presas nidos de Camponotus. Sin embargo, el éxito de cacería no siempre está garantizado (Lattke et al. 2007). Se observaron 284 especímenes, la mayoría capturados mediante colecta directa y necrotrampas. Los machos fueron recolectados en sitios cercanos a fuentes de luz.

A continuación, se presenta la clave dicotómica para la determinación de especies y subespecies de hormigas legionarias para Jalisco.

1. Superficie cóncava de las uñas tarsales con un diente (Fig. 6d) ................................................... 2

-. Superficie cóncava de las uñas tarsales sin diente, lisa (Fig. 7e) ........................... Neivamyrmex.... 7

2. Escapo antenal delgado, anchura del ápice menor que un tercio de la longitud total del mismo (Fig. 4c); hormigas de aspecto delgado y cutícula lisa ..................... 3

-. Escapo antenal grueso, anchura del ápice mayor que un tercio de la longitud total del mismo (Fig. 22c); hormigas de aspecto robusto y cutícula rugosa (Fig. 22)

Nomamyrmex: $N$. esenbeckii

3. Dorso del propodeo con presencia de espinas o dientes (Fig. 2b) .. Eciton ...................................... 4

-. Dorso del propodeo liso, redondeado, sin presencia de espinas o dientes (Fig. 6) ............. Labidus: L. coecus

4. Cabeza de los soldados de color amarillo opaco o castaño oscuro; procesos del propodeo en forma de dientes triangulares o redondeados en vista lateral (Figs. 2 b y 5 b); peciolo con apariencia ovoidal en vista dorsal (Figs. 2e y 5e)

-. Cabeza de los soldados de color marrón o castaño rojizo; procesos del propodeo en forma de espinas triangulares o espinas agudas en vista lateral (Figs. 3b y 4b); peciolo con apariencia semirectangular en vista dorsal (Figs. 3c

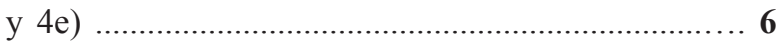

5. Cabeza de los soldados de color amarillo opaco; procesos propodeales en forma de dientes triangulares en vista dorsal-oblicua (Fig. 2d); mandíbulas de los soldados delgadas, ensanchadas en su base y adelgazadas hacia su región media (Fig. 2c)

\section{E. burchellii parvispinum}

-. Cabeza de los soldados de color castaño oscuro, procesos propodeales en forma de dientes redondeados en vista dorsal-oblicua (Fig. 5d), mandíbulas de los soldados robustas, con una constricción cerca de la base y con un fuerte ensanchamiento en su región media (Fig. 5c)

Eciton sp.

6. Procesos propodeales en forma de espinas agudas, parcial o completamente fusionadas o unidas por una carina en vista dorsal-oblicua (Fig. 3d) ... E. mexicanum

-. Procesos propodeales en forma de espinas triangulares, separadas, nunca fusionadas o unidas por una carina en vista dorsal-oblicua (Fig. 4d) .... E. vagans angustatum

7. Cabeza con escultura rugosa o granulosa ...........8 
-. Cabeza con escultura lisa y brillante, con puntuaciones dispersas .. 12

8. Superficie basal interna de las mandíbulas gradualmente curveada hasta alcanzar la superficie masticadora (Fig. 19d); ángulos posterolaterales de la cabeza con presencia de cuernos, proyecciones o dientes (Fig. 19c)

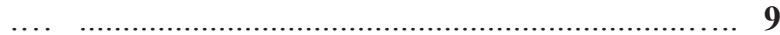

-. Superficiebasal interna de las mandíbulas recta, formando un ángulo casi recto en su unión con la superficie masticadora (Fig. 18d); ángulos posterolaterales de la cabeza proyectándose ligeramente, pero sin la presencia de cuernos o dientes (Fig. 18) ............ N. rugulosus

9. Cabeza y mesosoma densamente rugosos o granulosos, pero nunca con presencia de numerosas depresiones circulares con apariencia de pequeños pozos; hormigas de color castaño rojizo .

10

- Cabeza y mesosoma rugosos, con presencia de numerosas depresiones circulares que aparentan pequeños pozos (Fig. 19c); hormigas de color negro a castaño oscuro rojizo

N. sumichrasti

10. Ángulos posterolaterales de la cabeza proyectándose moderadamente o con presencia de pequeños dientecillos (Fig. 14b) .................................. 11

- Ángulos posterolaterales de la cabeza proyectándose fuertemente, con apariencia de cuernos (Fig. 9)

N. cornutus

11. Unión de la superficie dorsal y descendente del propodeo hasta formar un ángulo ligeramente redondeado; peciolo tan alto como largo en vista lateral (Fig. 21d)

N. texanus

-. Unión de la superficie dorsal y descendente del propodeo redondeada, nunca formando un ángulo; peciolo más largo que alto en vista lateral (Fig. 14d) ... N. nigrescens

12. Ojos ausentes o reducidos a un pequeño punto por debajo de la cutícula; córnea convexa ausente; longitud del escapo antenal no excede la mitad de la cabeza (Fig.

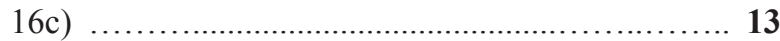

-. Ojos presentes, representados por un omatidio; córnea convexa presente; longitud del escapo antenal alcanza o excede la mitad de la cabeza (Fig. 13c) ....

15

13. Sutura entre el promesonoto y la mesopleura incompleta en vista lateral (Fig. 16d); peciolo rectangular o subcuadrado, menor o 1.5 veces más largo que ancho en vista dorsal (Fig.16a) ..................................... 14

-. Sutura entre el promesonoto y la mesopleura completa en vista lateral (Fig. 7d); peciolo ovalado y alargado, al menos 1.5 o 2.0 veces más largo que ancho en vista dorsal (Fig. 7a)

N. agilis

14. Margen dorsal del propodeo distintivamente mayor que la superficie descendente vista de perfil (Fig. 16d); obreras mayores con un tamaño menor a $3.5 \mathrm{~mm}$ (Fig.16) ............................................. pauxillus

- Margen dorsal del propodeo distintivamente menor que la superficie descendente vista de perfil (Fig. 20d); obreras mayores con un tamaño mayor a $4.0 \mathrm{~mm}$ (Fig.20) N. swainsonii
15. Carinas frontales estrechas o interrumpidas de manera abrupta justo al frente de las inserciones antenales, nunca formando una lamela hacia los costados (Fig. 8c); peciolo con forma rectangular en vista dorsal (Fig. 8d) ...16

-. Carinas frontales curvadas al frente de las inserciones antenales, formando una lamela que se va estrechando hacia los costados de manera gradual (Fig. 11c); peciolo con forma semicuadrada en vista dorsal (Fig. 11d)

N. harrisii

16. En vista dorsal, la porción cóncava del margen posterior de la cabeza aparenta ser ligeramente más angosta que el ancho máximo del mesosoma (Fig. 10a); proceso anteroventral del peciolo puntiagudo o distintivamente angular, ocasionalmente muy pequeño (Fig.10d) ... 17

-. En vista dorsal, la porción cóncava del margen posterior de la cabeza aparenta ser tan amplia o más, que el ancho máximo del mesosoma (Fig. 15a); proceso anteroventral del peciolo sutilmente redondeado o ausente (Fig.15d) ..

17. Cabeza de color castaño oscuro o negro .............. 18

-. Cabeza de color castaño amarillento o castaño rojizo

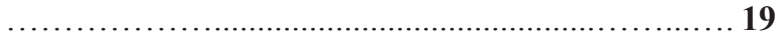

18. Cabeza, mesosoma y gáster del mismo color, castaño oscuro; proceso anteroventral del peciolo prominente y agudo, en forma de una espina dirigida posteroventralemente (Fig.17) ................ pilosus

-. Cabeza y gáster del mismo color, negro o castaño oscuro; mesosoma de color rojizo; proceso anteroventral del peciolo pequeño, dirigido ventralmente (Fig. 13) .........

N. melanocephalus

19. Proceso anteroventral del peciolo largo y triangular, con el ápice dirigido posteroventralmente (Fig. 10d); lamelas al frente de las inserciones antenales estrechas o ausentes (Fig. 10c) ........................... graciellae

- Proceso anteroventral del peciolo espinoso, con el ápice dirigido ventralmente (Fig. 12d); lamelas al frente de las inserciones antenales presentes, amplias (Fig. 12c) ......

N. impudens

20. Pospeciolo de la misma longitud que el peciolo en vista dorsal (Fig. 8d) .......................... chamelensis

-. Pospeciolo de menor longitud que el peciolo en vista dorsal (Fig. 15d) ....................... opacithorax

\section{DISCUSIÓN}

La revisión de material biológico depositado en las colecciones entomológicas, sumado a las muestras obtenidas durante el trabajo de campo en municipios y localidades no explorados del estado, incrementaron en un $36.8 \%$, de 19 a 26 especies y subespecies, la riqueza de hormigas legionarias para Jalisco (Watkins 1986, 1988; Vásquez-Bolaños 2008, 2015). Este nuevo valor de riqueza ubica al estado en el segundo lugar a nivel nacional, únicamente superado por Veracruz, pero en el primero en cuanto al número de especies de dorilinas en el occidente 
del país (Vásquez-Bolaños 2015; Janicki et al. 2016).

De las 26 especies y subespecies registradas, 21 correspondieron a registros previos para el estado (publicados en literatura dispersa), dos a nuevas morfoespecies (posibles nuevas especies para la ciencia) y tres a primeros registros para la entidad. La lista incluye a $N$. fuscipennis, que fue registrada por primera vez para Jalisco por Alatorre-Bracamontes et al. (2015), así como a $N$. mandibularis, considerada como subespecie de $N$. pilosus, pero actualmente erigida como especie válida (Snelling y Snelling 2007).

Aunque esta riqueza es ligeramente menor a la de lista 29 especies dentro de cinco géneros citada en Antmaps (Janicki et al. 2016); la diferencia de siete especies más en comparación con nuestro registro de 26 especies, se debe a que en Antmaps la presencia de algunas especies en el estado no está validada con referencias bibliográficas, como Cheliomyrmex morosus. Además, aunque para Jalisco solo se han registrado ciertas subespecies, Antmaps incluye también a las especies como taxones diferentes; así, cita a E. burchellii y E. burchellii parvispinum, a E. vagans y E. vagans angustatum, así como a $N$. esenbeckii y $N$. esenbeckii mordax. También, Antmaps menciona especies cuyos registros para Jalisco no existen: Neivamyrmex californicus de California en Estados Unidos de América (Alatorre-Bracamontes et al. 2015); así como N. gibbatus, una especie determinada erróneamente que corresponde a ejemplar de $N$. graciellae (P. S. Ward com. pers.).

\section{AGRADECIMIENTOS}

El primer autor agradece al Consejo Nacional de Ciencia y Tecnología (CONACYT) por la beca de posgrado (becario: 629143), a la Secretaria de Educación Jalisco y al Sindicato Nacional de Trabajadores de la Educación (Sección 47) por la licencia y el apoyo para la realización del posgrado a través de la Beca-Comisión otorgada, en especial al Mtro. Miguel Rodríguez Noriega, Dr. Luis Roldán García, Mtro. Salvador Bracamontes Mariscal y Lic. Verónica Delgado. A la Coordinación de la Maestría en Ciencias en Biosistemática y Manejo de Recursos Naturales y Agrícolas, en especial a la Dra. Patricia Zarazúa Villaseñor, por la asesoría y apoyo otorgados para la realización de estancias en México y el extranjero. A los curadores de las colecciones entomológicas visitadas por las facilidades para la revisión del material: Dr. José Luis Navarrete-Heredia - CZUG, M. en C. Enrique RamírezGarcía-EEBC, Dra. Gabriela Castaño-Meneses-LESMA, Dr. Alejandro Saldívar-Riverón y M. en C. Cristina Mayorga-CNIN. Al M. en R. B. Hugo Fierros López por las enseñanzas y asesoría brindada para la elaboración de las ilustraciones y láminas. Al Dr. Benjamín Hernández Márquez, por la asesoría y consejos brindados en el manejo y análisis de softwares estadísticos. Al Urb. Gerardo García de León por la ayuda y los consejos brindados en el manejo de herramientas de diseño. A la IRNA Margarita Villalvazo Palacios, por el apoyo recibido en el trabajo de campo. Finalmente, a los compañeros del Laboratorio de Entomología de la Universidad de Guadalajara por el apoyo otorgado en el trabajo de laboratorio y campo. A los revisores por sus valiosas observaciones para enriquecer el escrito.

\section{LITERATURA CITADA}

Alatorre-Bracamontes, C. E., M. Vásquez-Bolaños, G. Castaño-Meneses y J. L. Navarrete-Heredia. 2015. La subfamilia Dorylinae (Hymenoptera: Formicidae) en la Colección Entomológica, Sección Formicidae del Centro de Estudios en Zoología, Universidad de Guadalajara (pp. 41-51). In: Castaño-Meneses, G., M. Vásquez-Bolaños, J. L. Navarrete-Heredia, G. A. Quiroz-Rocha y I. Alcalá-Martínez (Eds.). Avances de Formicidae de México. Astra Ediciones, S. A. de C. V., Guadalajara, Jalisco, México.

AntWeb. 2015. AntWeb v6.3.3. Subfamily: Dorylinae Leach, 1815. http://www.antweb.org/description. do? subfamily $=$ dorylinae $\&$ rank $=$ subfamily\&project $=$ allantwebants. Fecha de consulta: 28 de mayo de 2015.

AntWeb. 2016a. Project: Bolton World Catalog. https://www.antweb.org/taxonomicPage.do?rank= species\&project=worldants. Fecha de consulta: 24 de mayo de 2016.

AntWeb. 2016b. AntWeb v6.6.8. Specimen: CASENT0104811 Neivamyrmex pauxillus. https://www.antweb.org/getComparison. do?genus $=$ neivamyrmex\&species $=$ pauxillus $\&$ rank $=$ species\&adm 1 Name $=$ Louisiana\&pr $=$ d. Fotografía por April Nobile. Fecha de consulta: 15 de febrero de 2016.

AntWeb. 2016c. AntWeb v6.6.8. Specimen:

CASENT0249500 Neivamyrmex pilosus. https://www.antweb.org/specimenImages.do? name $=$ casent0249500. Fotografía por Will Ericson. Fecha de consulta: 15 de febrero de 2016.

Bolton, B. 1990. Army ants reassessed: the phylogeny and classification of the doryline section (Hymenoptera: Formicidae). Journal of Natural History, 24: 13391364.

Bolton, B. 2003. Synopsis and classification of Formicidae. Memoirs of the American Entomological Institute, 71:1370.

Bolton, B., G. Albert, P. S. Ward and P. Naskrecki. 2006. Bolton's catalogue of ants of the world: 1758-2005. Harvard University Press, Cambridge, Massachusetts. CD.

Brady, S. G., B. L. Fisher, T. R. Schultz and P. S. Ward. 2014. The raise of the army ants and their relatives: diversification of specialized predatory doryline ants. BMC Evolutionary Biology, 14: 1-14.

CONABIO. 2008a. Provincias biogeográficas de México. Catálogo de metadatos geográficos. Comisión Nacional para el Conocimiento y Uso de la Biodiversidad. http://www.conabio.gob.mx/informacion/metadata/gis/ rbiog4mgw.xml?_httpcache=yes\&_xsl=/db/metadata/ 
xsl/fgdc_html.xsl\&_indent=no. Fecha de consulta: 14 de abril de 2015 .

CONABIO.2008b. Vegetación potencial. Catálogo de metadatos geográficos. Comisión Nacional para el Conocimiento y Uso de la Biodiversidad.

http:/www.conabio.gob.mx/informacion/metadata/gis /vpr4mgw.xml?_httpcache=yes\&_xsl=/db/metadata/ xsl/fgdc_html.xsl\&_indent=no. Fecha de consulta: 30 de marzo de 2016.

Gottwald, W. H. 1979. Phylogenetic implications of army ant zoogeography (Hymenoptera: Formicidae). Annals of the Entomological Society of America, 72 (4): 462467.

Jaffé, K. C. 1993. El mundo de las hormigas. Editorial Equinoccio, Universidad Simon Bolivar. Edo. Miranda, Venezuela.

Janicki, J., N. Narula, M. Ziegler, B. Guénard and E. P. Economo. 2016. Visualizing and interacting with large-volume biodiversity data using client-server webmapping applications: The design and implementations of antmaps.org. Ecological Informatics, 32: 185-193.

Kronauer, D. J. C. 2009. Recent advances in army ant biology (Hymenoptera: Formicidae). Myrmecological News, 12: 51-65.

Lattke, J. E., M. Kaspari, S. O’Donnell y S. Powell. 2007. Las hormigas ecitoninas de Venezuela (Hymenoptera: Formicidae: Ecitoninae) elenco preliminary. Entomotropica, 22 (3): 153-170.

Longino, J. T. 2016. Labidus coecus (Latreille, 1802). http://academic.evergreen.edu/projects/ants/genera/ labidus/species/coecus/coecus.html. Fecha de consulta: 7 de junio de 2016.

Morón, M. A. y R. A. Terrón. 1984. Distribución altitudinal $\mathrm{y}$ estacional de los insectos necrófilos en la sierra norte de Hidalgo, México. Acta Zoológica Mexicana (nueva serie), (3): 1-47.

Morrone, J. J. 2005. Hacía una síntesis biogeográfica de México. Revista Mexicana de Biodiversidad, 76 (2): 207- 252.

Morrone, J. J. and J. Márquez. 2008. Biodiversity of Mexican terrestrial arthropods (Arachnida and Hexapoda): A Biogeographical puzzlee. Acta Zoológica Mexicana (nueva serie), 24 (1): 15-41.

O’Donnell, S., J. Lattke, S. Powell and M. Kaspari. 2007. Army ants in four forests: geographic variation in raid rates and species composition. Journal of Animal Ecology, 76: 580-589.

Palacio, E. E. 2003. Subfamilia Ecitoninae (pp. 281-285). In: Fernández F. (Ed.). Introducción a las hormigas de la región Neotropical. Instituto de Investigación de Recursos Biológicos Alexander von Humboldt, Bogotá, Colombia.

Quiroz-Robledo, L. N. y J. Valenzuela-González. 2004. Las Hormigas Ecitoninae (Hymenoptera: Formicidae) de Morelos, México. Revista de Biología Tropical, 54 (2): 531-552.
Quiroz-Robledo, L. N., J. Valenzuela-González y T. SuárezLanda. 2002. Las hormigas ecitoninas (Formicidae: Ecitoninae) de la Estación Biológica Tropical "Los Tuxtlas", Veracruz, México. Folia Entomológica Mexicana, 41 (3): 261-281.

Rico-Gray, V. and P. S. Oliveira, 2007. The ecology and evolution of ant-plant interactions. The University of Chicago Press, Chicago.

Ríos-Casanova, L. 2014. Biodiversidad de hormigas en México. Revista Mexicana de Biodiversidad, 85 (Supl.): 392-398.

Rojas, P. y A. Cartas. 1997. Ecitoninae (pp. 349-353). In: González-Soriano, E., R. Dirzo y R. C. Vogt (Eds.). Historia Natural de Los Tuxtlas. Universidad Nacional Autónoma de México, México, D. F.

Rzedowski, J. 2006. Vegetación de México. 1ra. Edición digital, Comisión Nacional para el Conocimiento y Uso de la Biodiversidad, México.

Snelling, G. C. and R. R. Snelling. 2007. New synonymy, new species, new keys to Neivamyrmex army ants of the United States (pp. 459-550). In: Snelling, R. R., B. L. Fisher and P. S. Ward (Eds.). Advances in ant systematics (Hymenoptera: Formicidae): homage to E. O. Wilson - 50 years of contributions. Memoirs of the American Entomological Institute, 80. Gainesville, Florida.

Varela-Hernández, F. and G. Castaño-Meneses. 2011. Neivamyrmex albacorpus, a new species of ant (Hymenoptera: Formicidae: Ecitoninae) from Metztitlán, Hidalgo, México. Sociobiology, 58 (3): 579584.

Vásquez-Bolaños, M. 1996. Neivamyrmex melanocephalus (Emery, 1859). Dugesiana, 3 (2): 36-37.

Vásquez-Bolaños, M. 2008. Hormigas ecitoninas (Hymenoptera: Formicidae) en cinco localidades del occidente de Jalisco. Entomología Mexicana, 7: 10171019.

Vásquez-Bolaños, M. 2011. Lista de especies de hormigas (Hymenoptera: Formicidae) para México. Dugesiana, 18 (1): 95-133.

Vásquez-Bolaños, M. 2015. Taxonomía de Formicidae (Hymenoptera) para México. Métodos en Ecología y Sistemática, 10 (1): 1-53.

Watkins, J. F. 1976. The identification and distribution of new world army ants (Dorylinae: Formicidae). Baylor University Press, Waco, Texas.

Watkins, J. F. 1982. The army ants of Mexico (Hymenoptera: Formicidae: Ecitoninae). Journal of the Kansas Entomological Society, 55 (2): 197-247.

Watkins, J. F. 1986. Neivamyrmex chamelensis, n. sp. (Hymenoptera: Formicidae: Ecitoninae) from Jalisco, Mexico. Journal of the Kansas Entomological Society, 59 (2): $361-366$.

Watkins, J. F. 1988. The army ants (Formicidae: Ecitoninae) of the Chamela Biological station in Jalisco, Mexico. Folia Entomológica Mexicana, 77: 379-393. 
Watkins, J. F. 1990. Neivamyrmex crassiscapus, n. sp. Wetterer, J. K. and G. C. Snelling. 2015. Geographic (Hymenoptera: Formicidae: Ecitoninae) from México. Journal of the Kansas Entomological Society, 63 (2): 348-350.

Recibido: 7 de junio 2019 distribution of Labidus coecus (Latr.) (Hymenoptera: Formicidae), a subterranean army ant. Journal of Hymenoptera Research, 44: 31-38. doi: 10.3897/ JHR.44.4672.

Aceptado: 1 de julio 2019
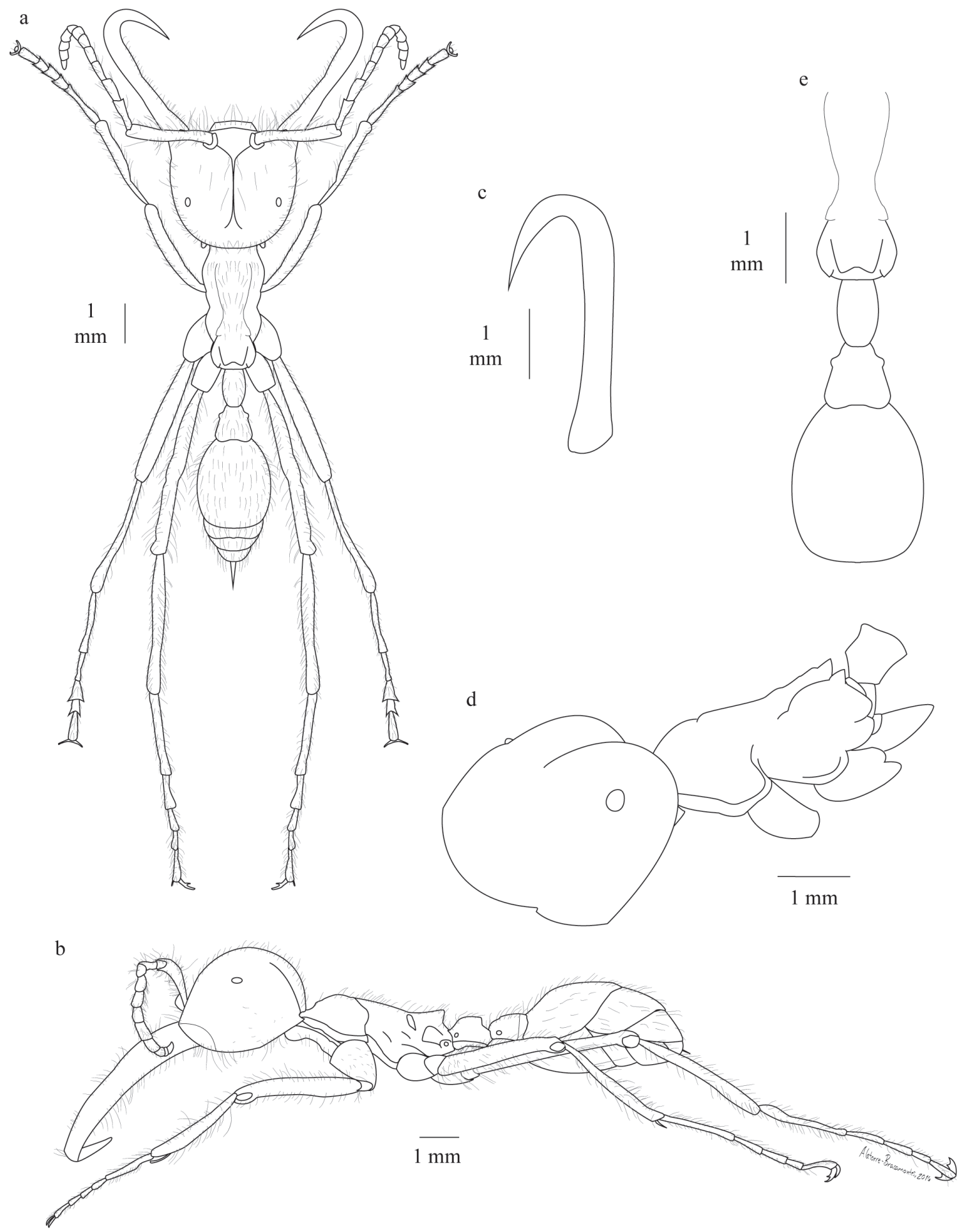

Figura 2. Soldado de Eciton burchellii parvispinum: a) vista dorsal, b) vista lateral, c) mandíbula (vista dorsal), d) vista dorsal-oblicua, e) peciolo y pospeciolo (vista dorsal). 

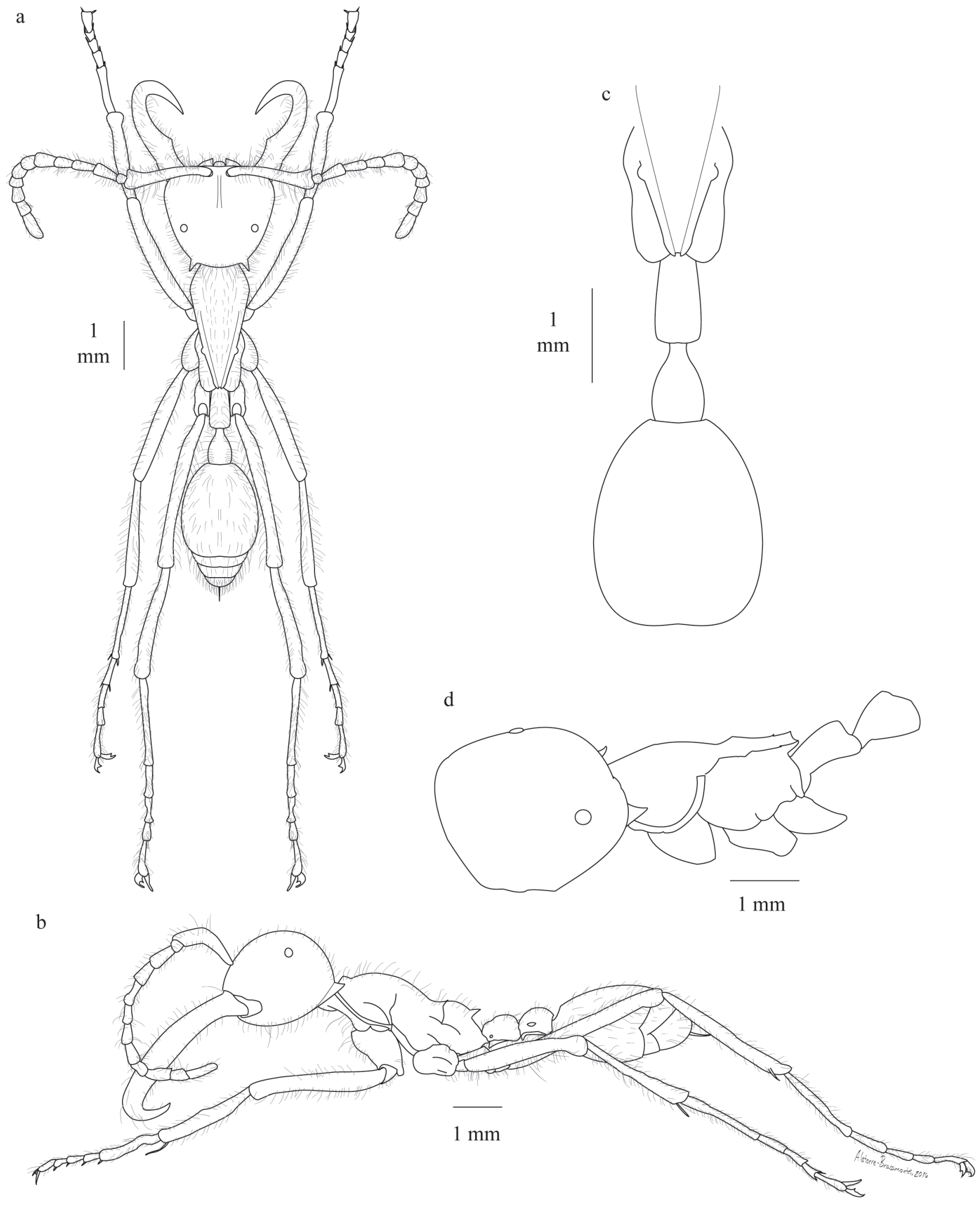

Figura 3. Soldado de Eciton mexicanum: a) vista dorsal, b) vista lateral, c) peciolo y pospeciolo (vista dorsal), d) vista dorsal-oblicua. 

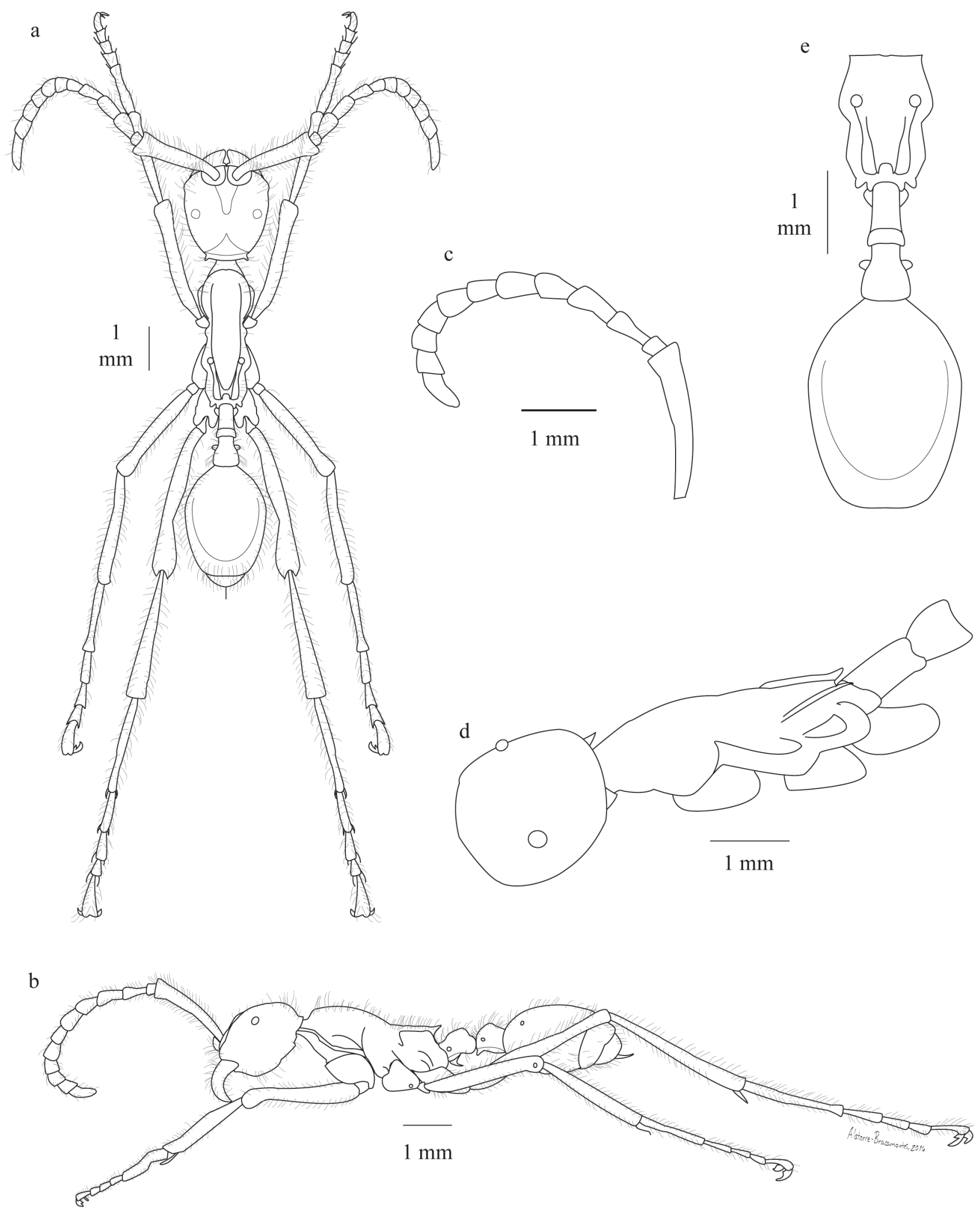

Figura 4. Obrera de Eciton vagans angustatum: a) vista dorsal, b) vista lateral, c) antena (vista lateral), d) vista dorsal-oblicua, e) peciolo y pospeciolo (vista dorsal). 

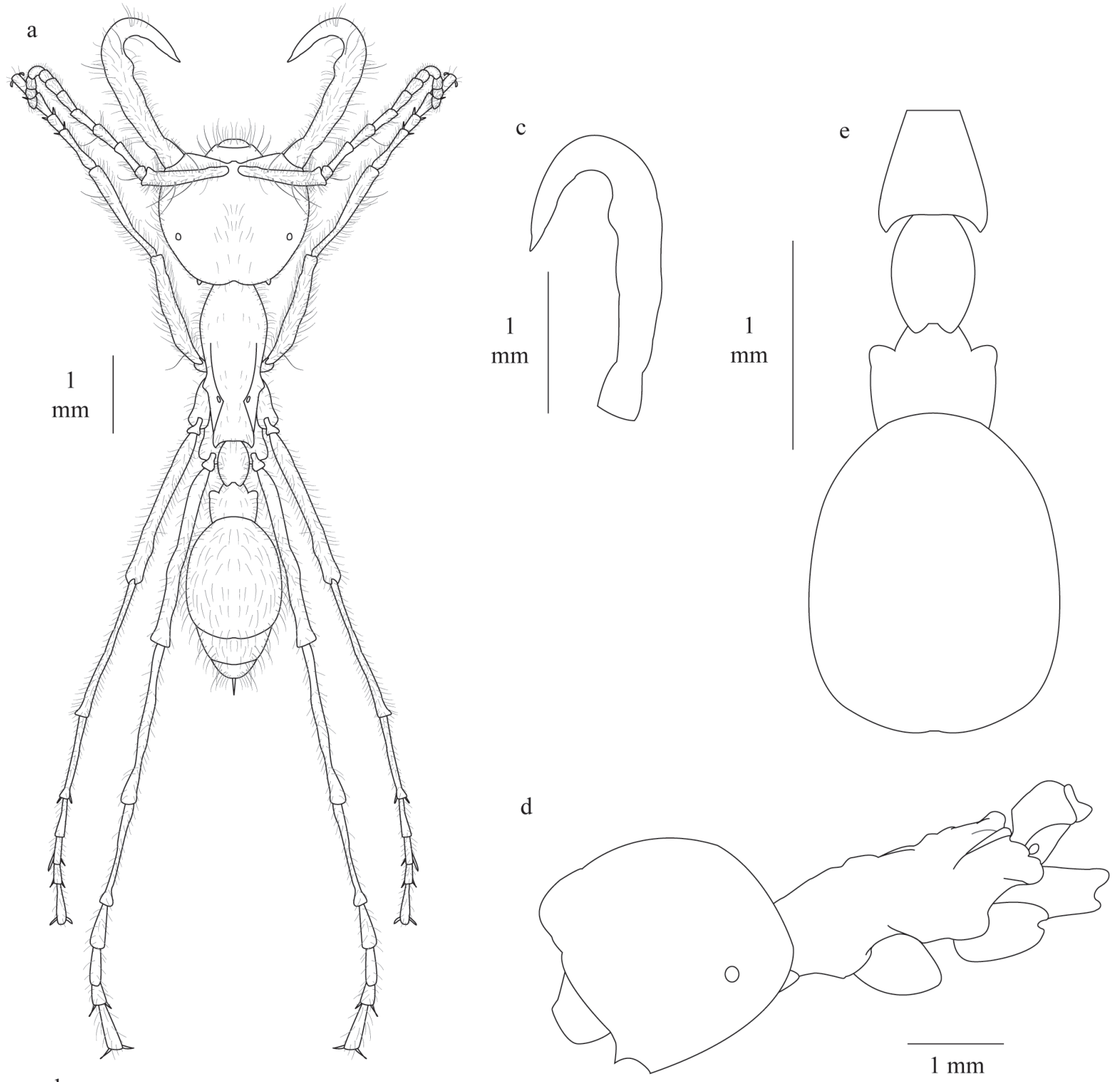

$\mathrm{b}$

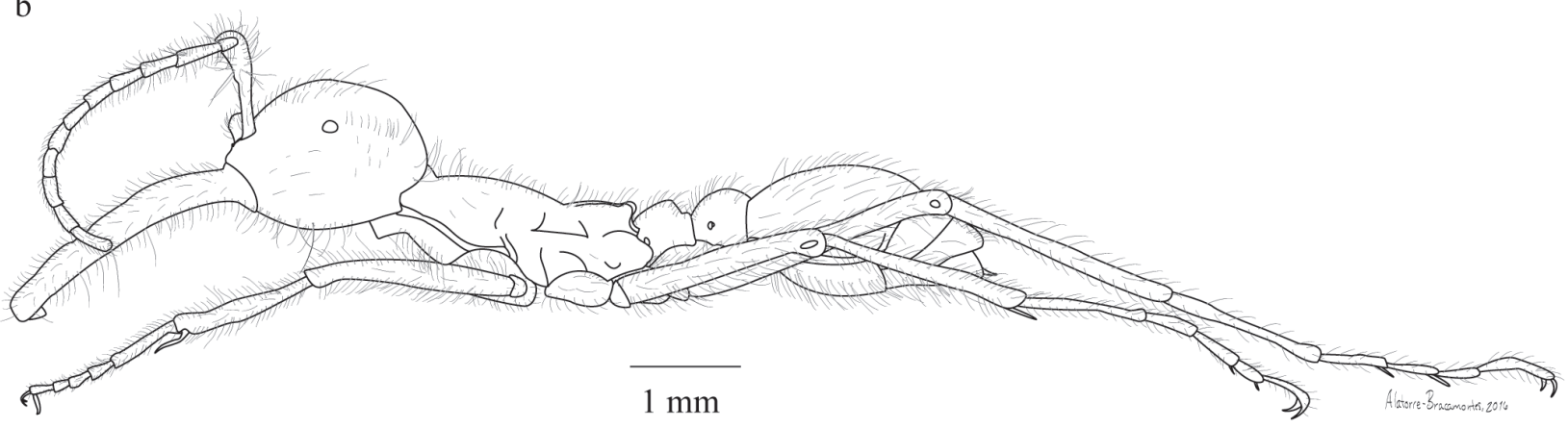

Figura 5. Soldado de Eciton sp.: a) vista dorsal, b) vista lateral, c) mandíbula (vista dorsal), d) vista dorsal-oblicua, e) peciolo y pospeciolo (vista dorsal). 
a

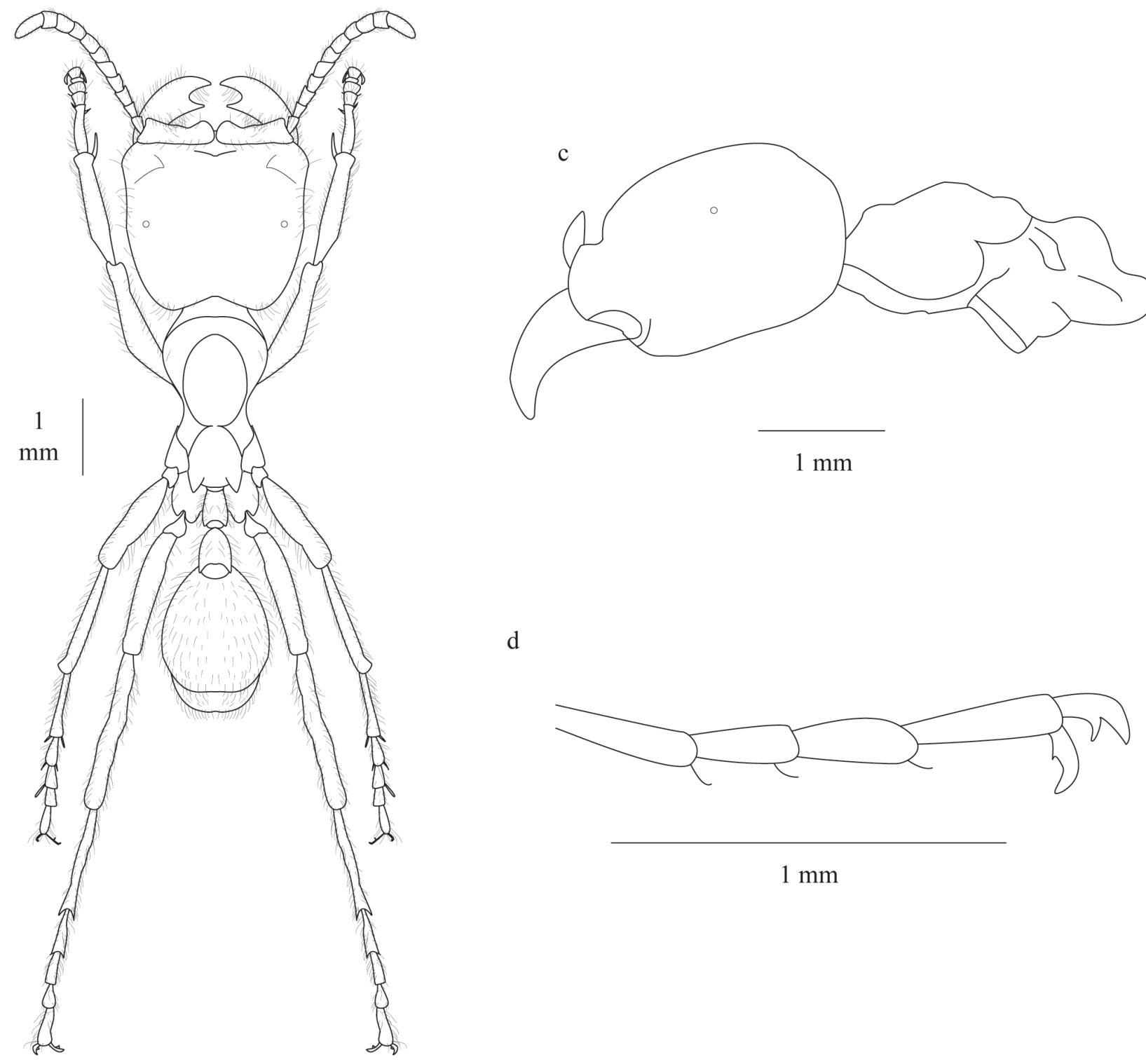

b

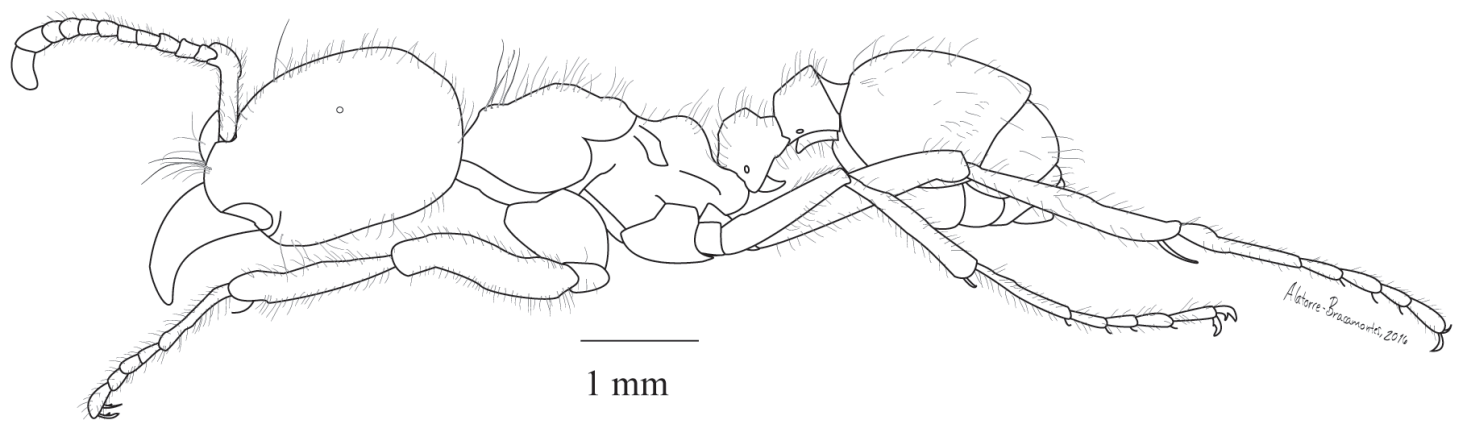

Figura 6. Soldado de Labidus coecus: a) vista dorsal, b) vista lateral, c) cabeza y mesosoma (vista lateral), d) mesotarso y uña tarsal (vista lateral). 
a

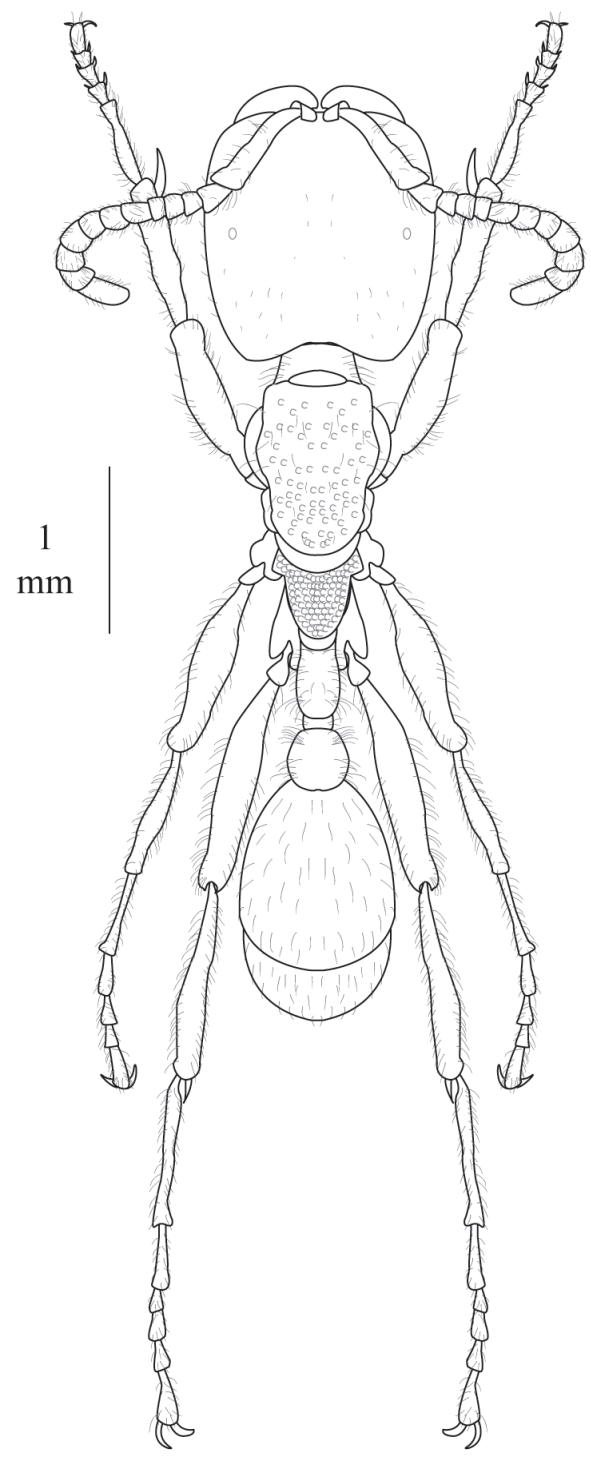

$\mathrm{c}$

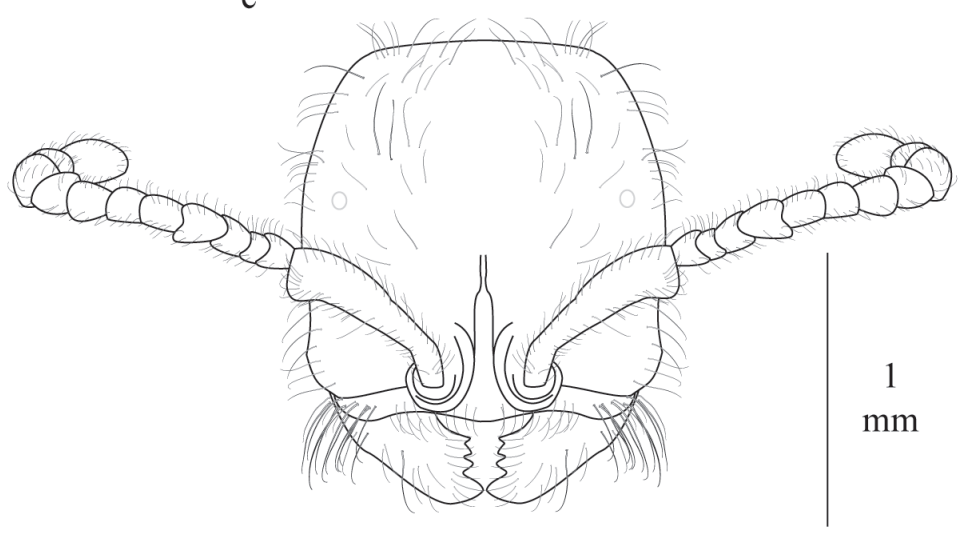

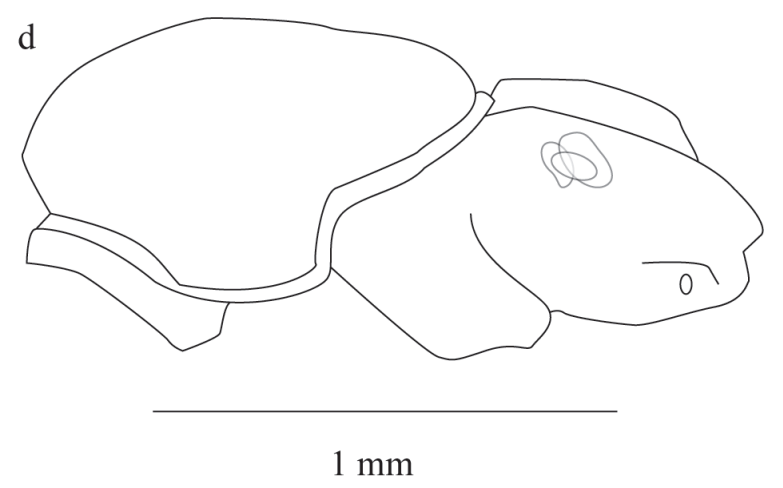

e

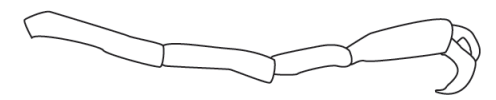

$1 \mathrm{~mm}$

$\mathrm{b}$

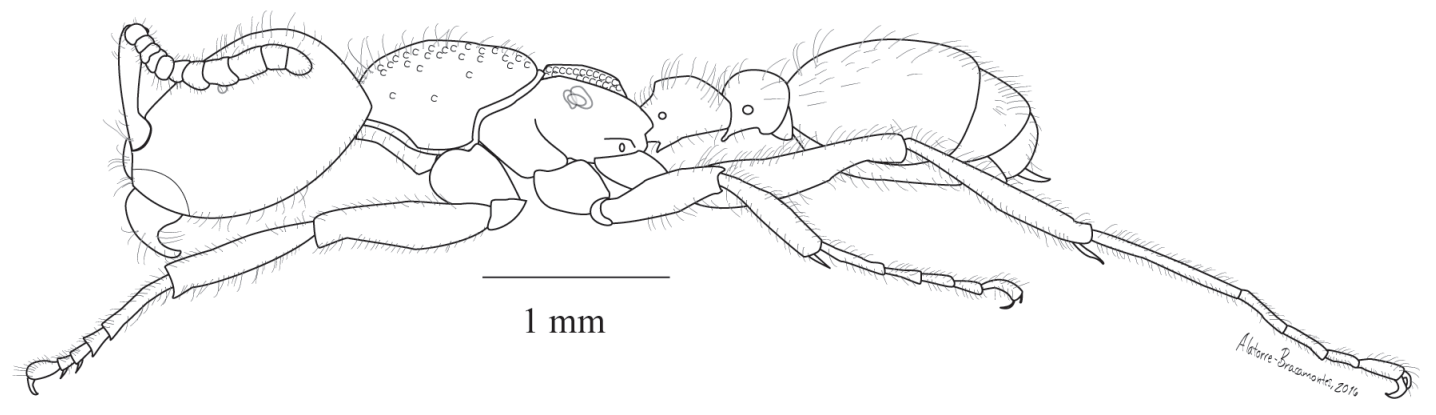

Figura 7. Soldado de Neivamyrmex agilis: a) vista dorsal, b) vista lateral, c) cabeza (vista frontal), d) mesosoma (vista lateral), e) metatarso y uña tarsal (vista lateral). 


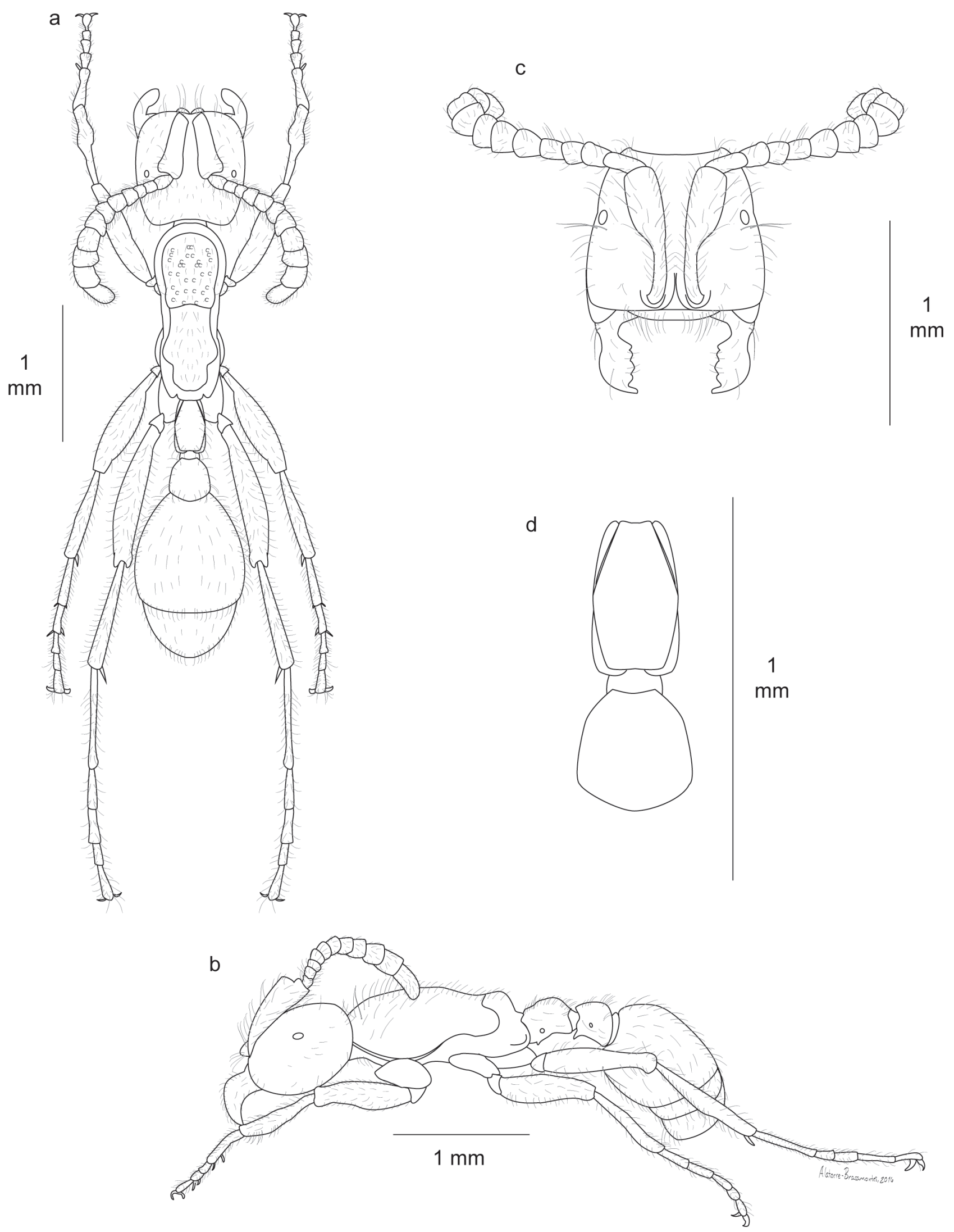

Figura 8. Obrera de Neivamyrmex chamelensis: a) vista dorsal, b) vista lateral, c) cabeza (vista frontal), d) peciolo y postpeciolo (vista dorsal). 


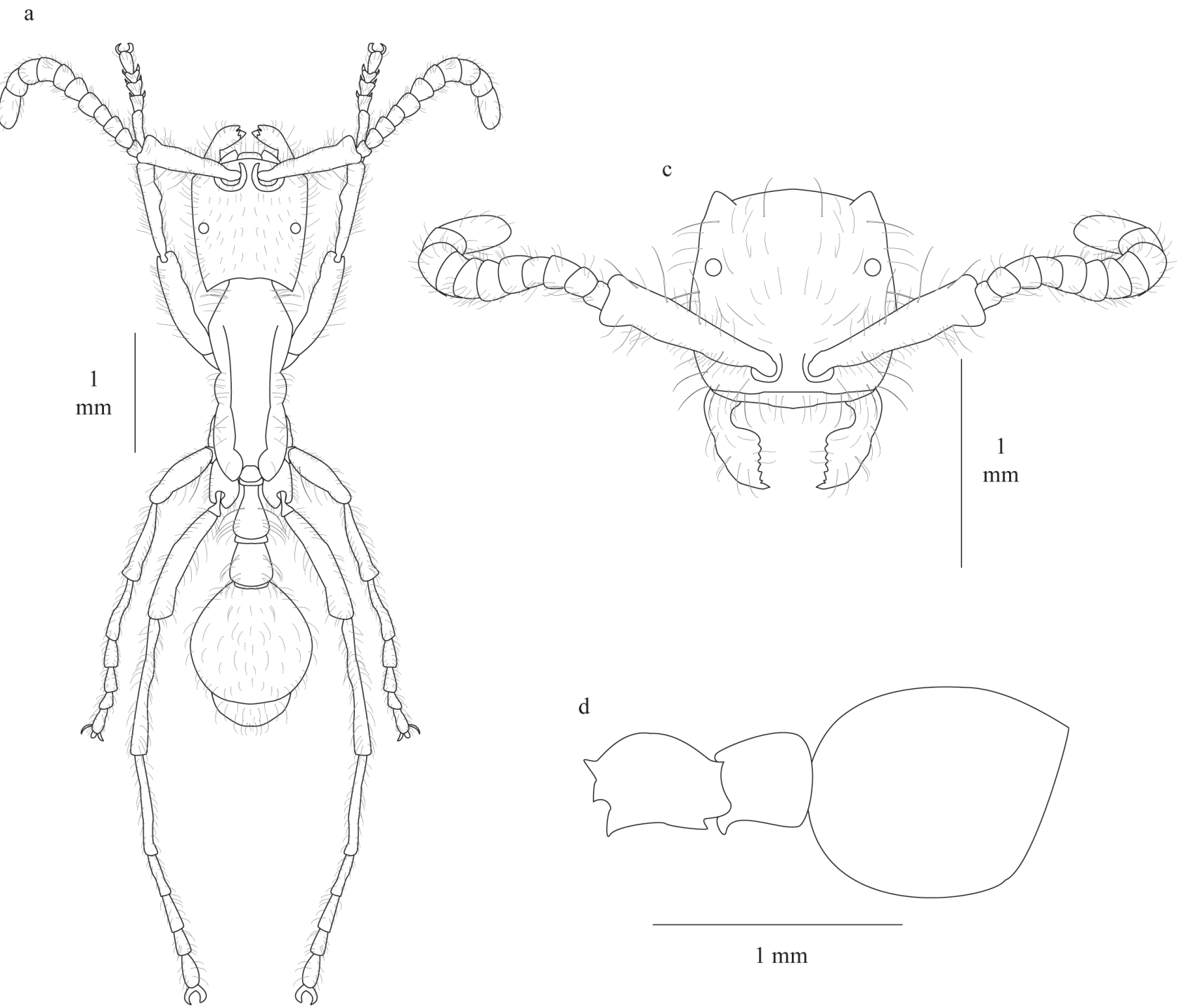

b

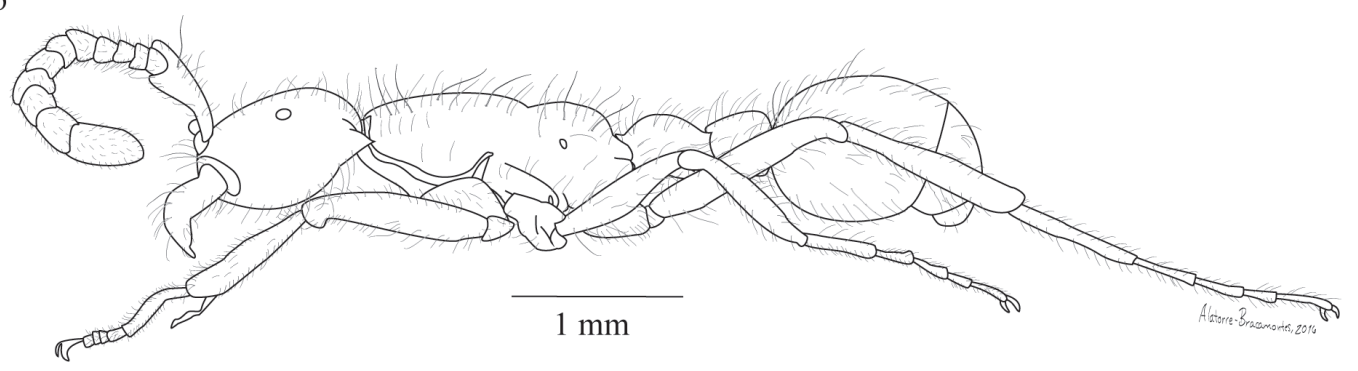

Figura 9. Obrera de Neivamyrmex cornutus: a) vista dorsal, b) vista lateral, c) cabeza (vista frontal), d) peciolo y pospeciolo (vista lateral). 

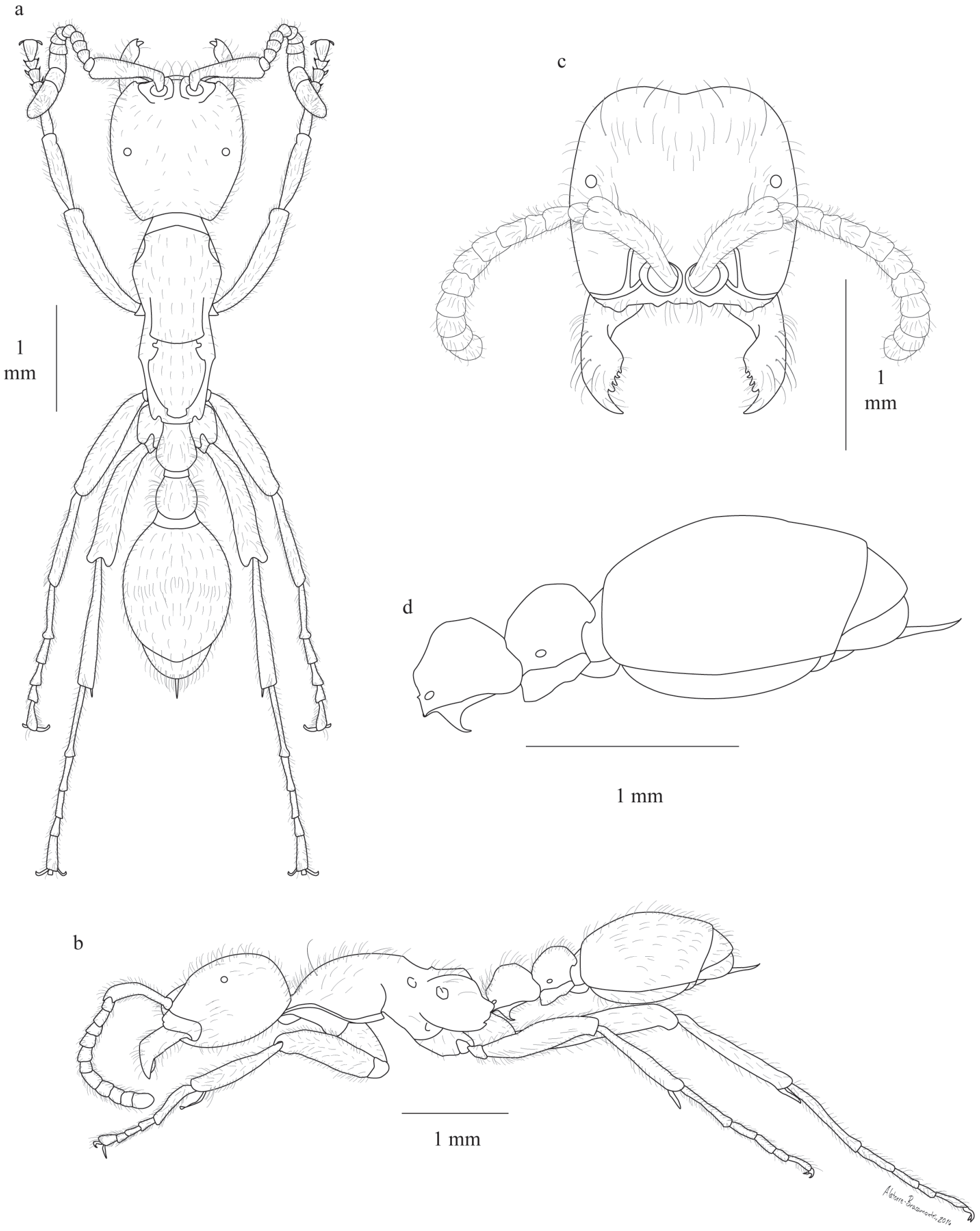

Figura 10. Obrera de Neivamyrmex graciellae: a) vista dorsal, b) vista lateral, c) cabeza (vista frontal), d) peciolo, pospeciolo y gáster (vista lateral). 
a

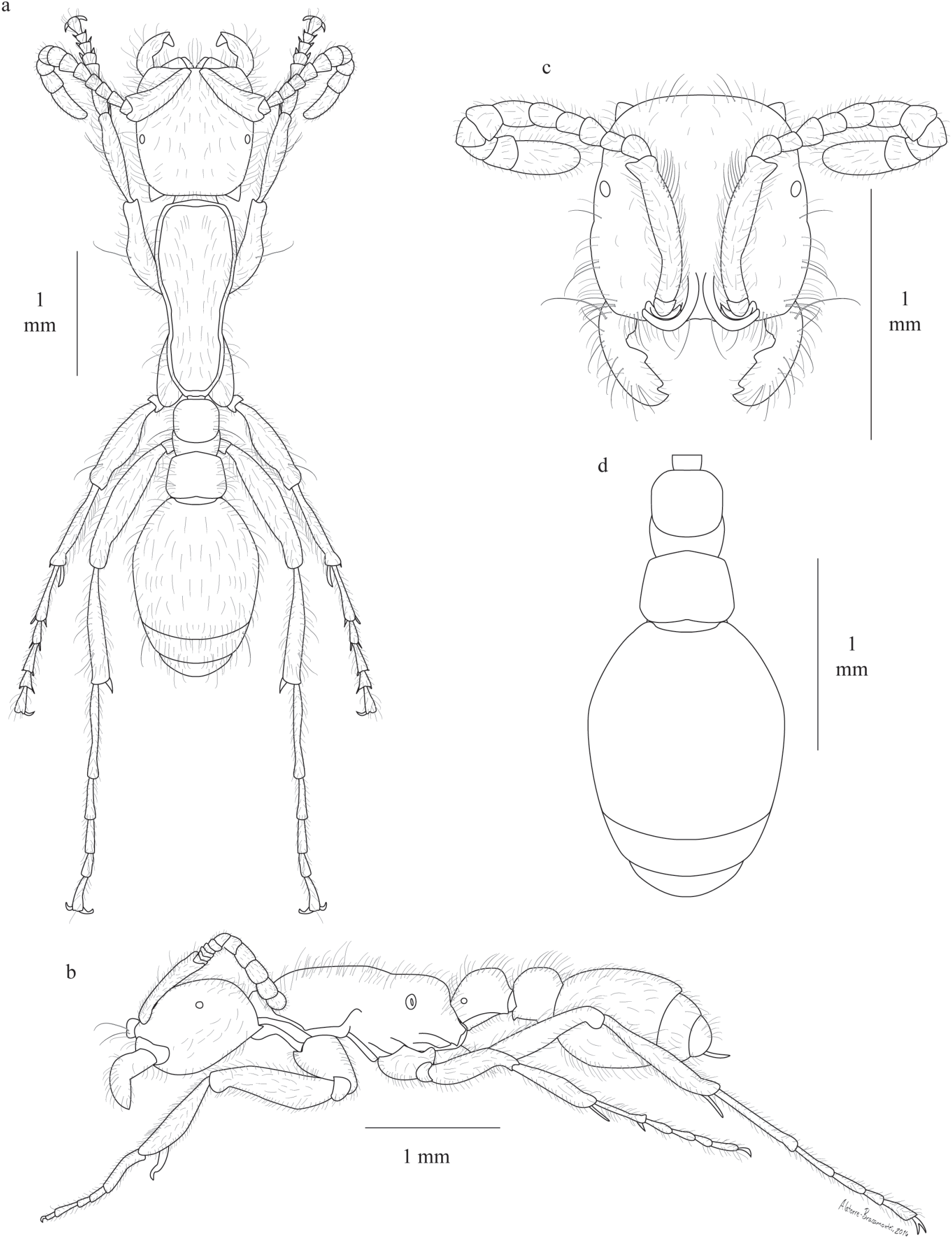

Figura 11. Obrera de Neivamyrmex harrisii: a) vista dorsal, b) vista lateral, c) cabeza (vista frontal), d) peciolo y pospeciolo (vista dorsal). 
a

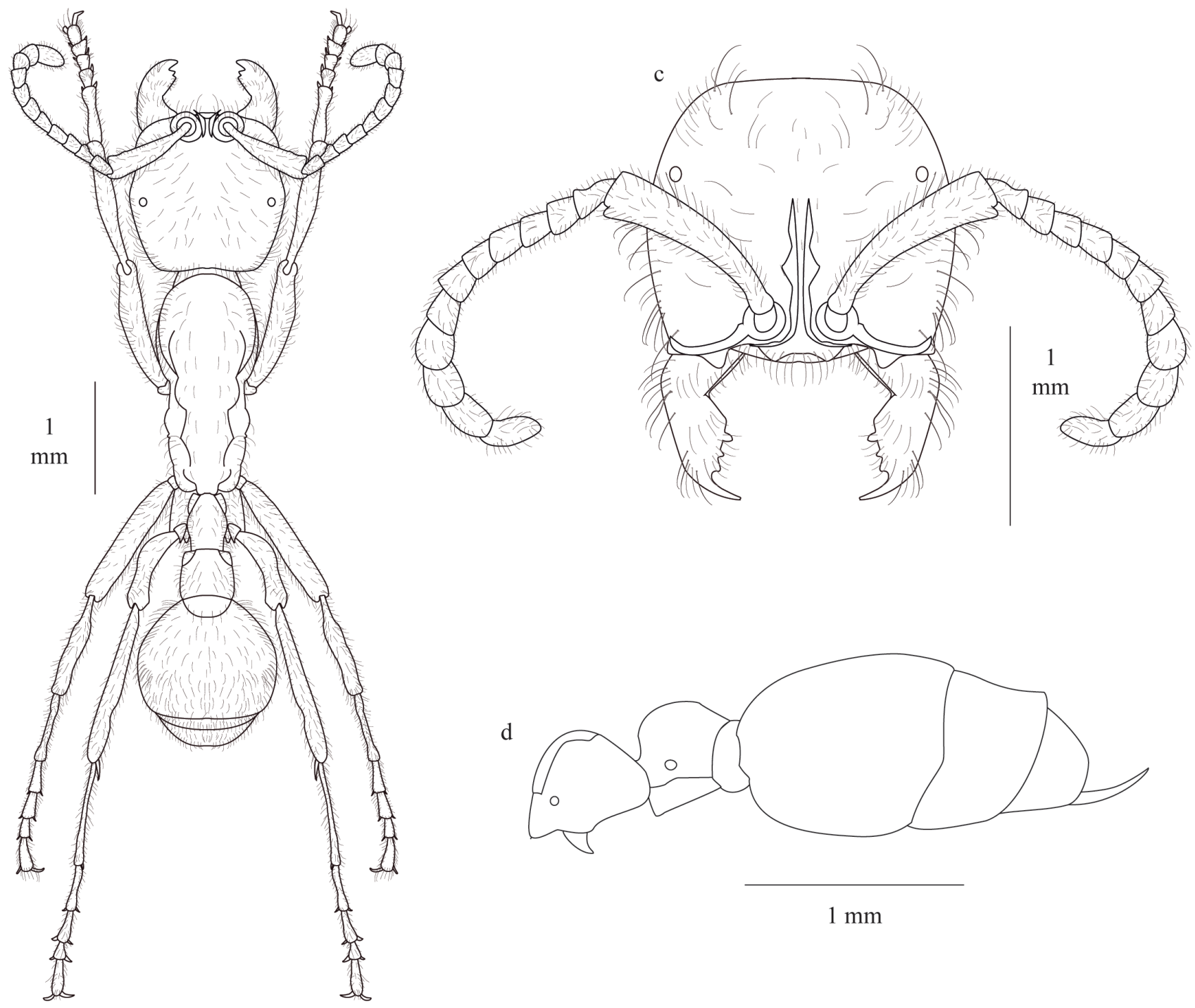

b

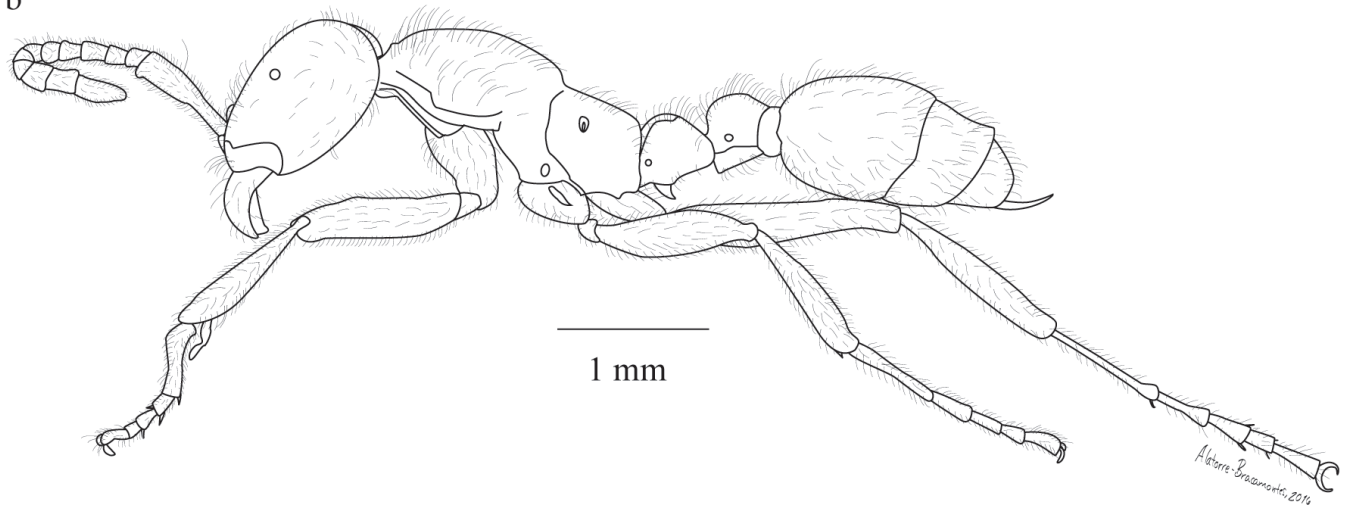

Figura 12. Obrera de Neivamyrmex impudens: a) vista dorsal, b) vista lateral, c) cabeza (vista frontal), d) peciolo y pospeciolo (vista lateral). 


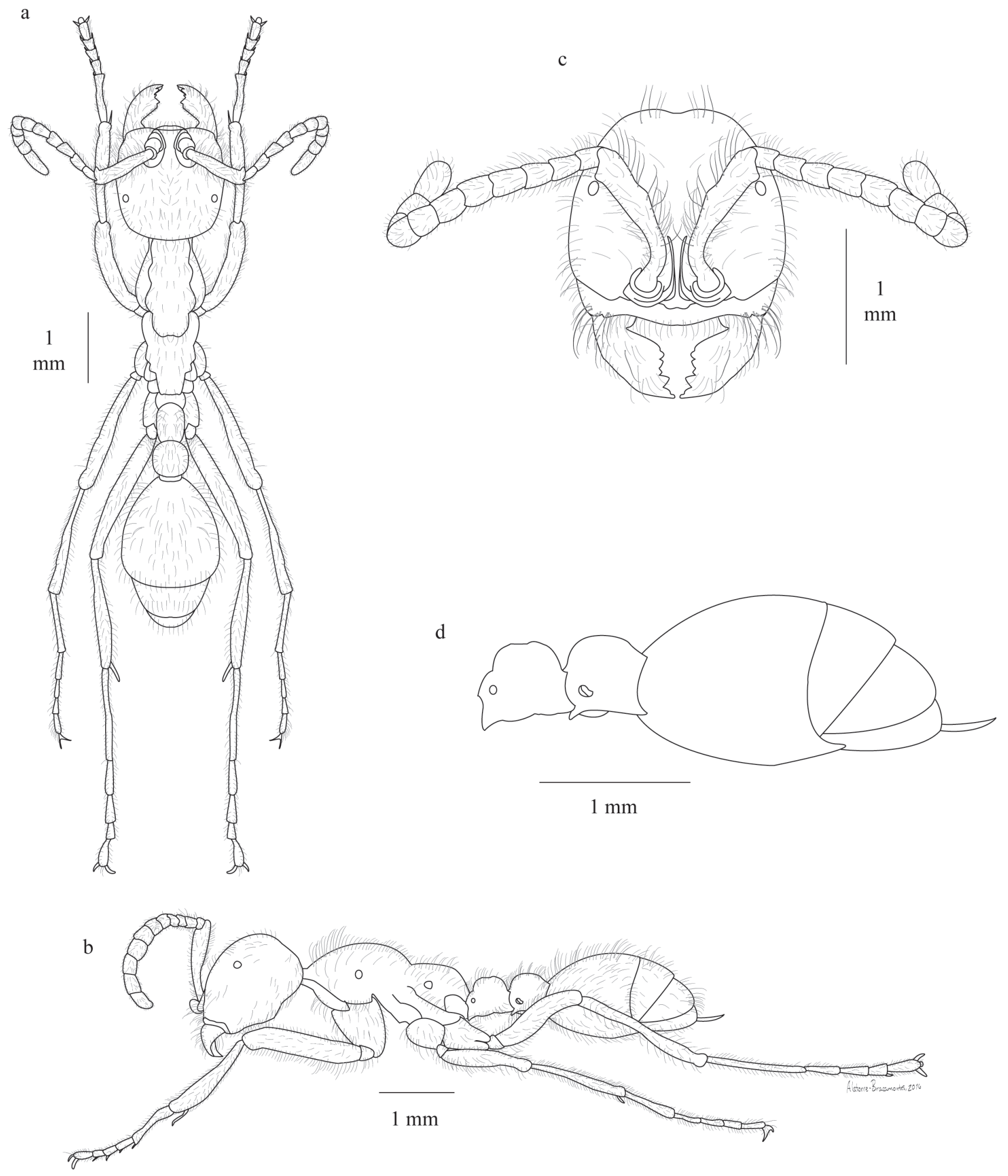

Figura 13. Soldado de Neivamyrmex melanocephalus: a) vista dorsal, b) vista lateral, c) cabeza (vista frontal), d) peciolo, pospeciolo y gáster (vista lateral). 
a
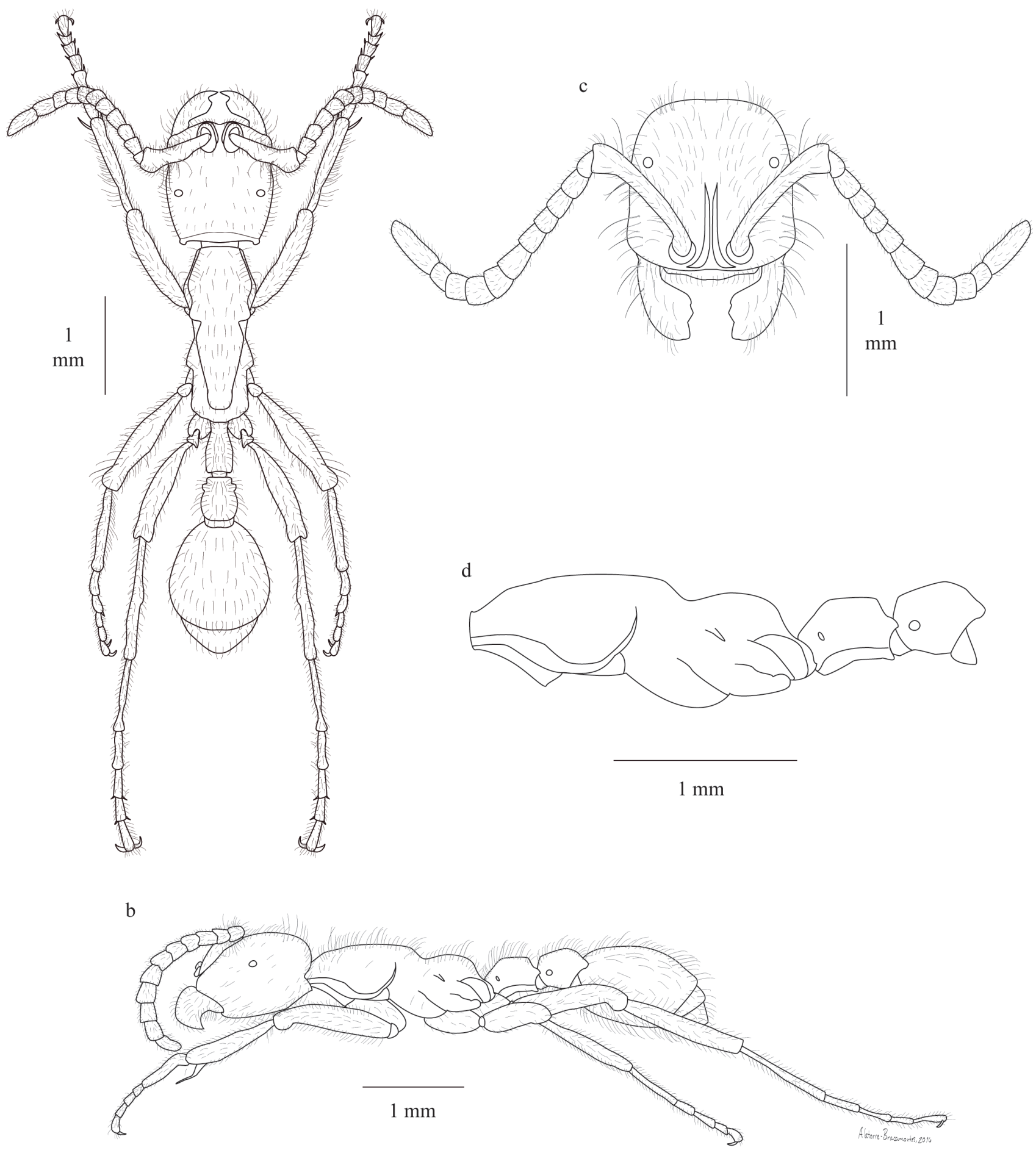

Figura 14. Obrera de Neivamyrmex nigrescens: a) vista dorsal, b) vista lateral, c) cabeza (vista frontal), d) mesosoma (vista lateral). 
a

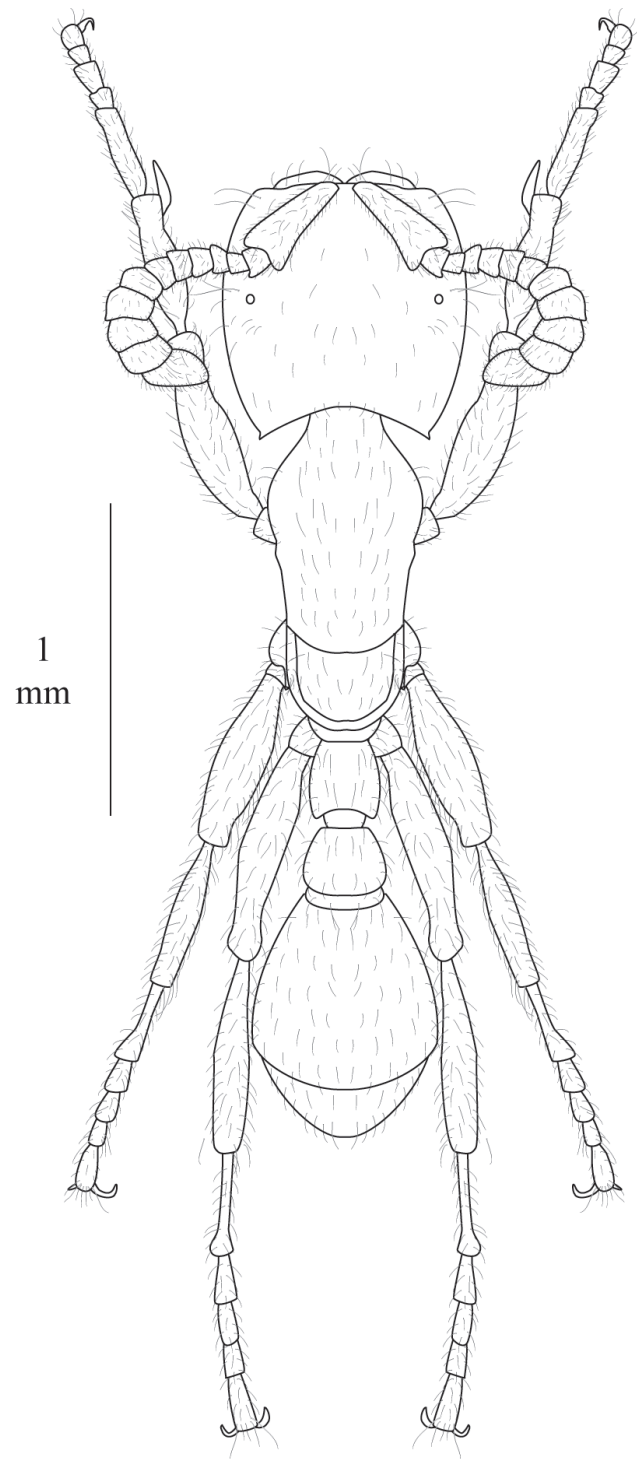

c

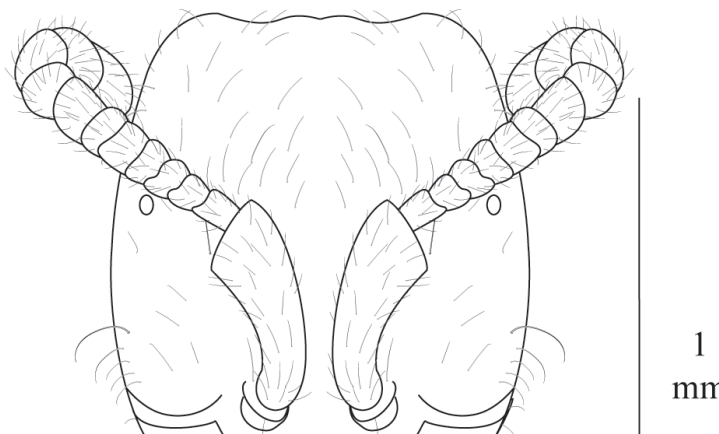

d

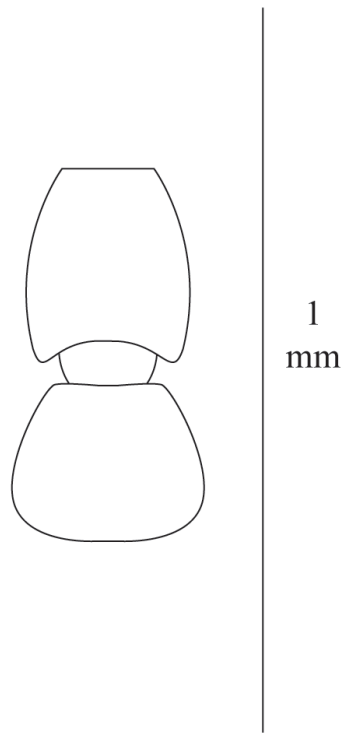

b

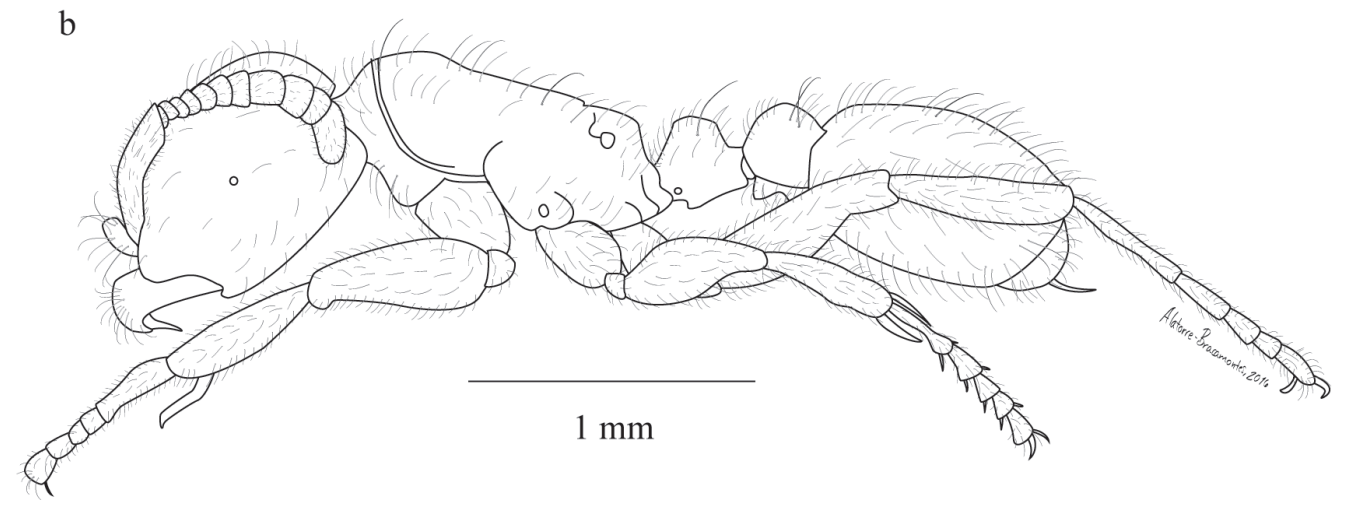

Figura 15. Obrera de Neivamyrmex opacithorax: a) vista dorsal, b) vista lateral, c) cabeza (vista frontal), d) peciolo y pospeciolo (vista dorsal). 

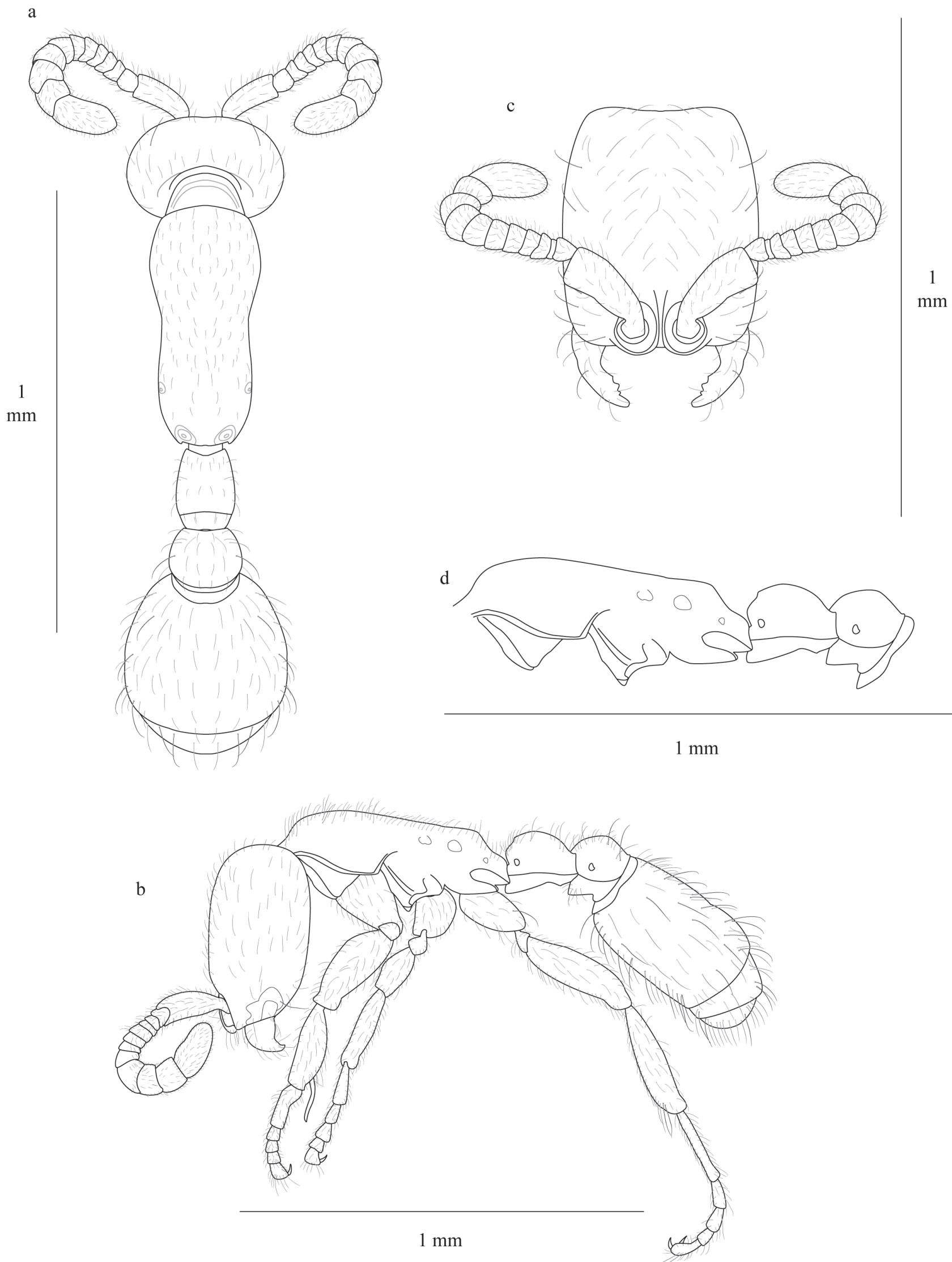

Figura 16. Obrera de Neivamyrmex pauxillus: a) vista dorsal, b) vista lateral, c) cabeza (vista frontal), d) mesosoma, peciolo y pospeciolo (vista lateral). Redibujada de AntWeb (2016b). Fotografía por April Nobile. 
a
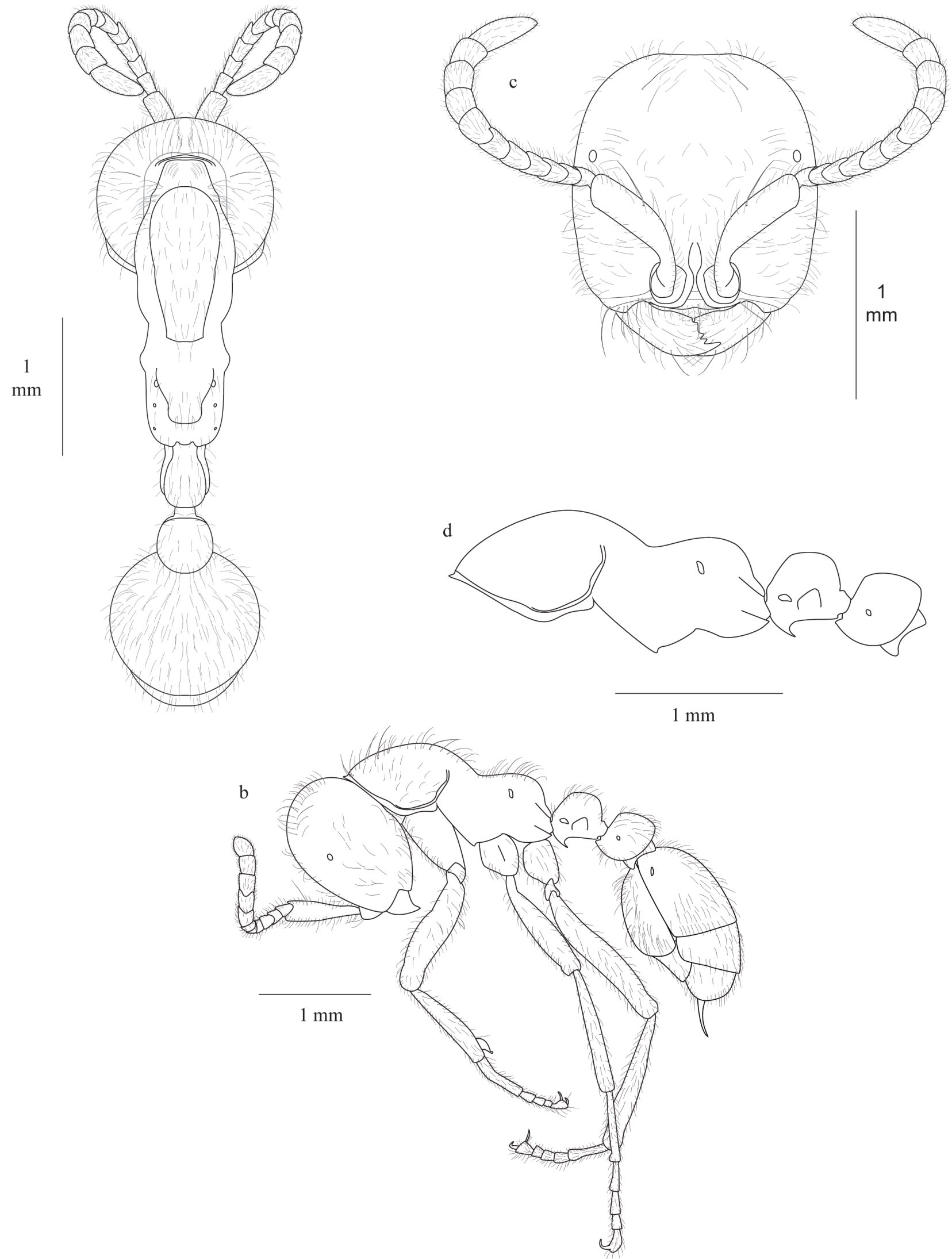

Figura 17. Obrera de Neivamyrmex pilosus: a) vista dorsal, b) vista lateral, c) cabeza (vista frontal), d) mesosoma (vista lateral). Redibujada de AntWeb (2016c). Fotografía por Will Ericson, (2012). 


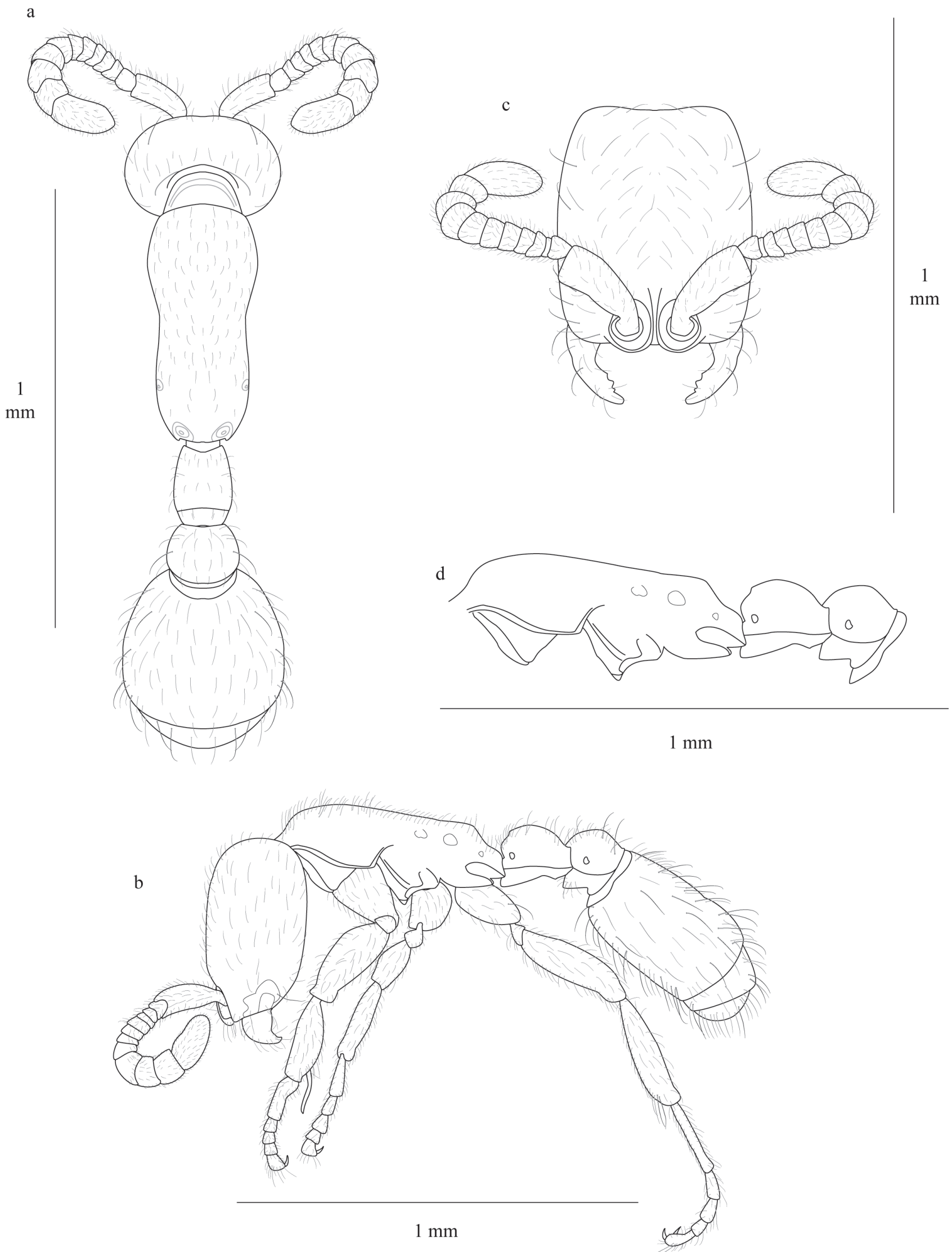

Figura 18. Obrera de Neivamyrmex rugulosus: a) vista dorsal, b) vista lateral, c) cabeza (vista frontal), d) mandíbula (vista frontal). 
a
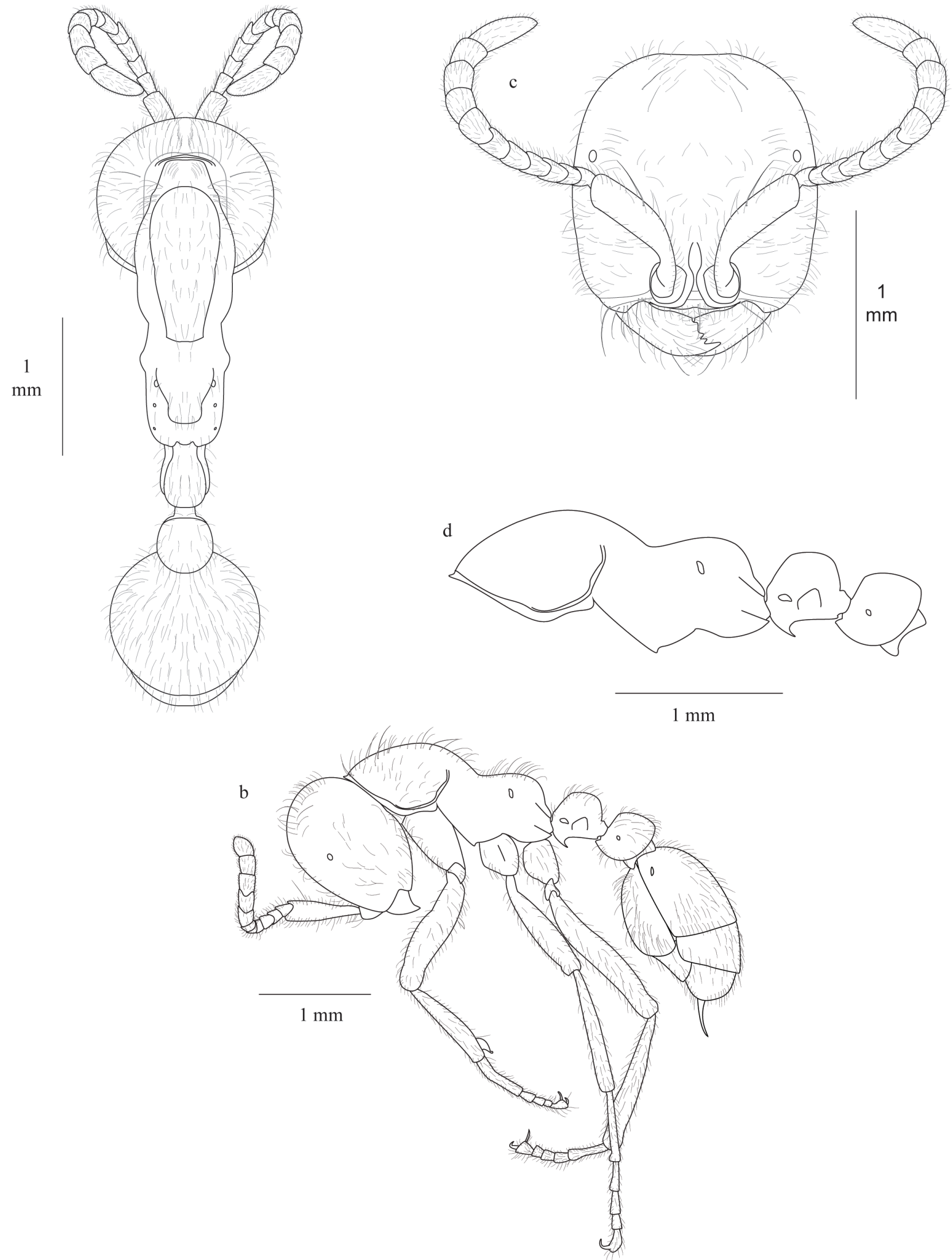

Figura 19. Obrera de Neivamyrmex sumichrasti: a) vista dorsal, b) vista lateral, c) escultura cefálica (cabeza, vista frontal), d) mandíbula (vista frontal). 
a
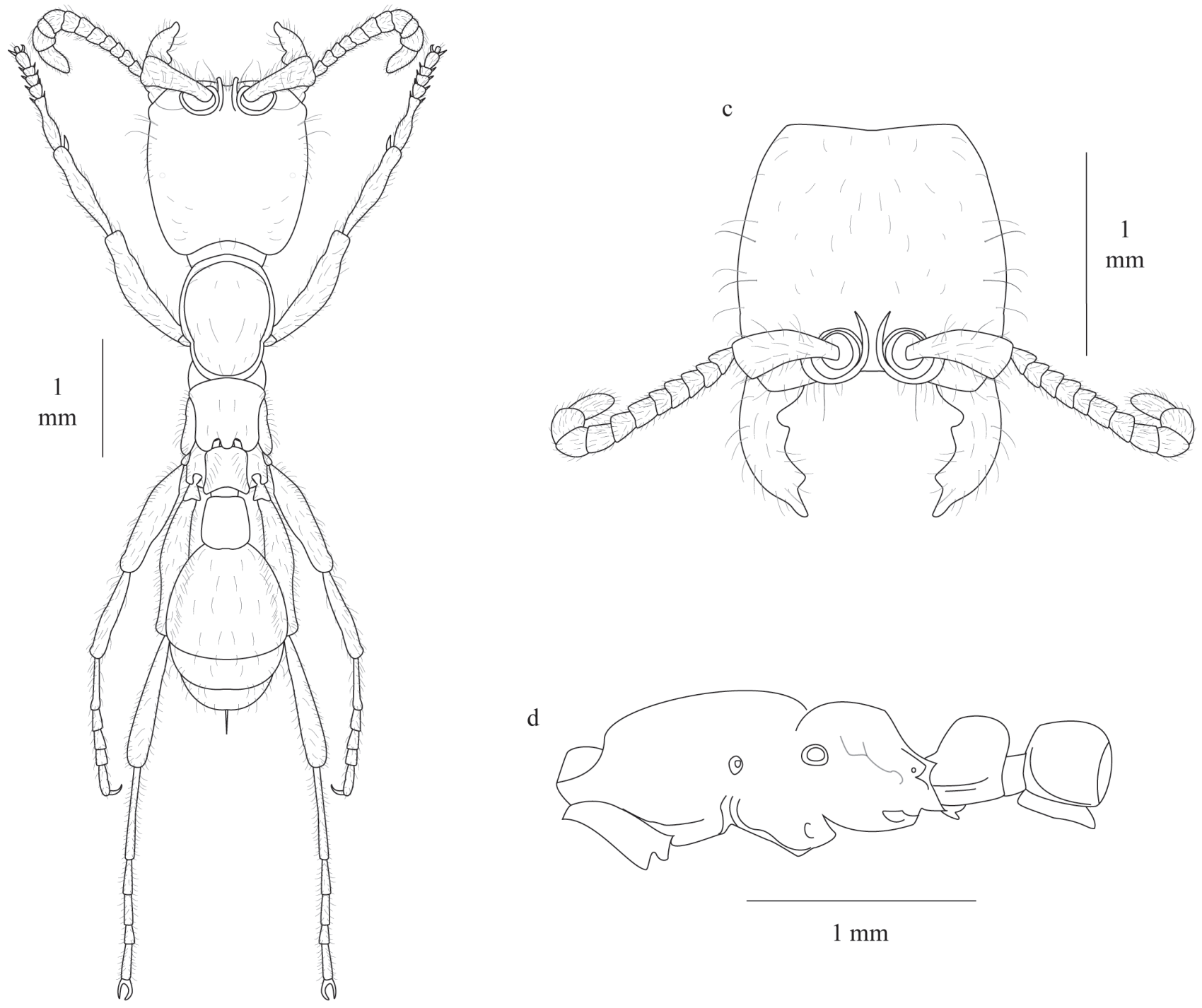

$\mathrm{d}$

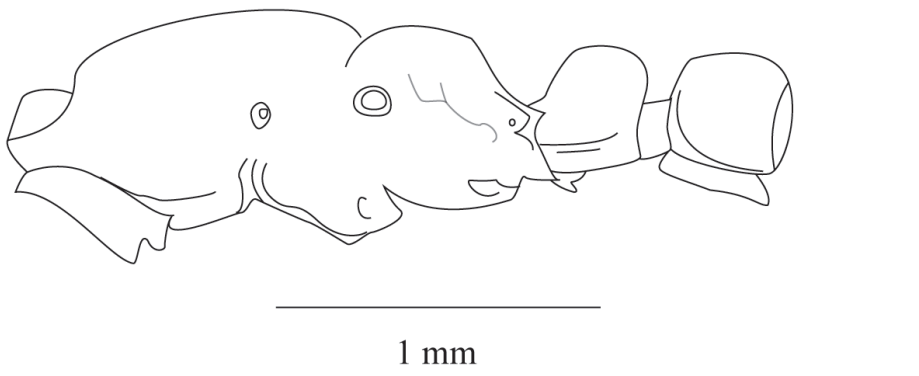

b

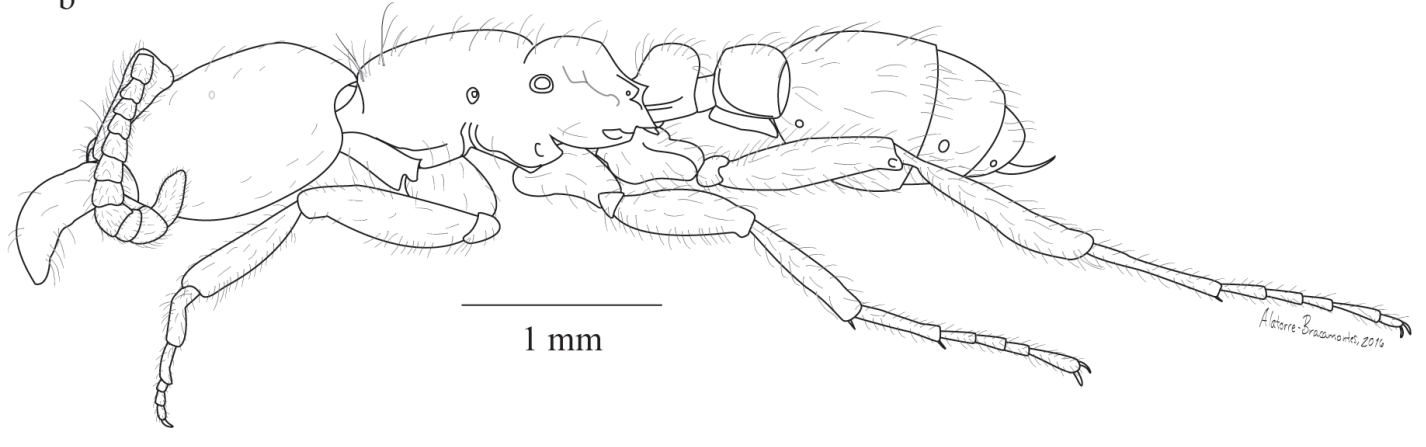

Figura 20. Obrera de Neivamyrmex swainsonii: a) vista dorsal, b) vista lateral, c) cabeza (vista frontal), d) mesosoma, peciolo y pospeciolo (vista lateral). 
a
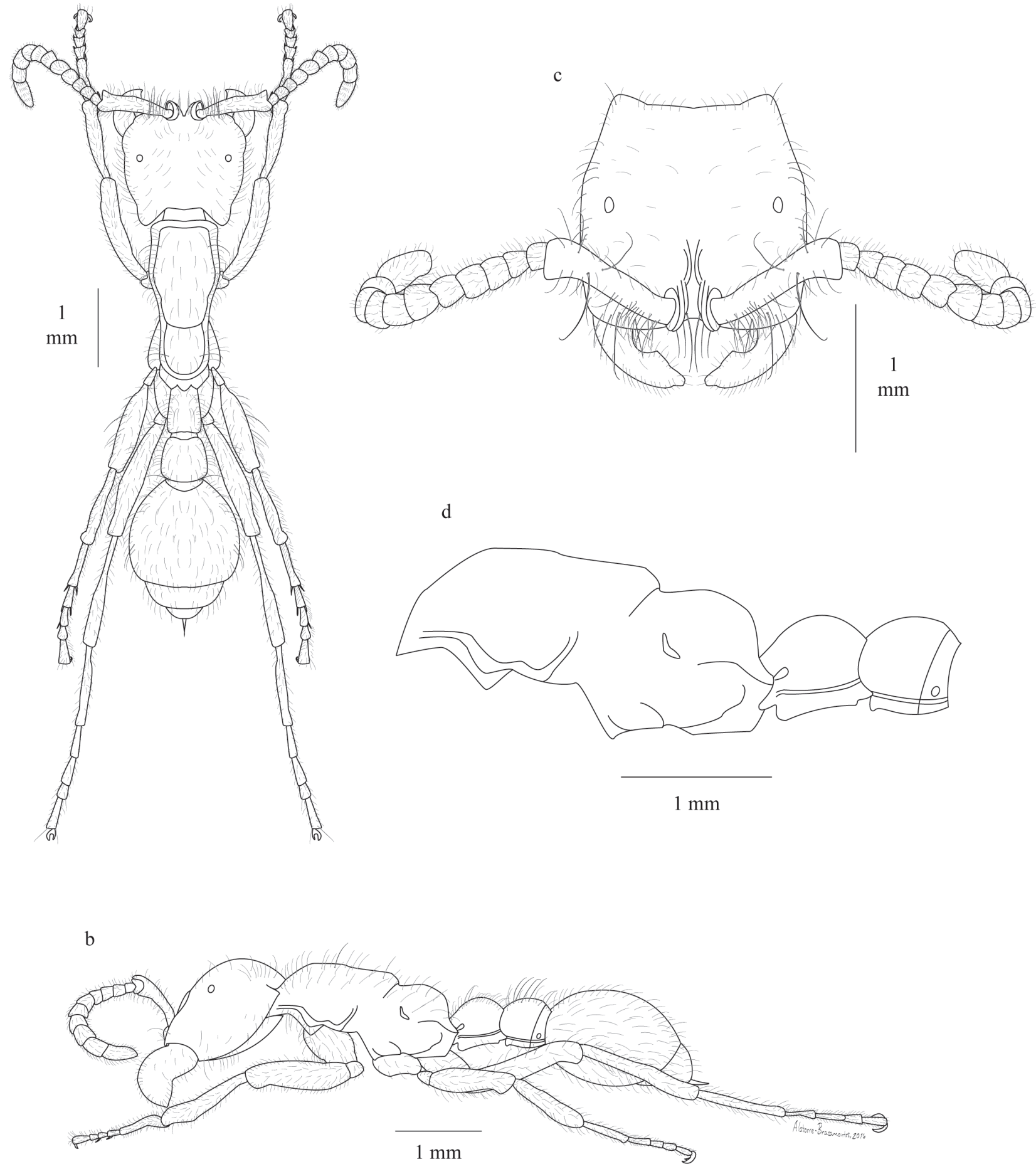

Figura 21. Soldado de Neivamyrmex texanus: a) vista dorsal, b) vista lateral, c) cabeza (vista frontal), d) mesosoma (vista lateral). 


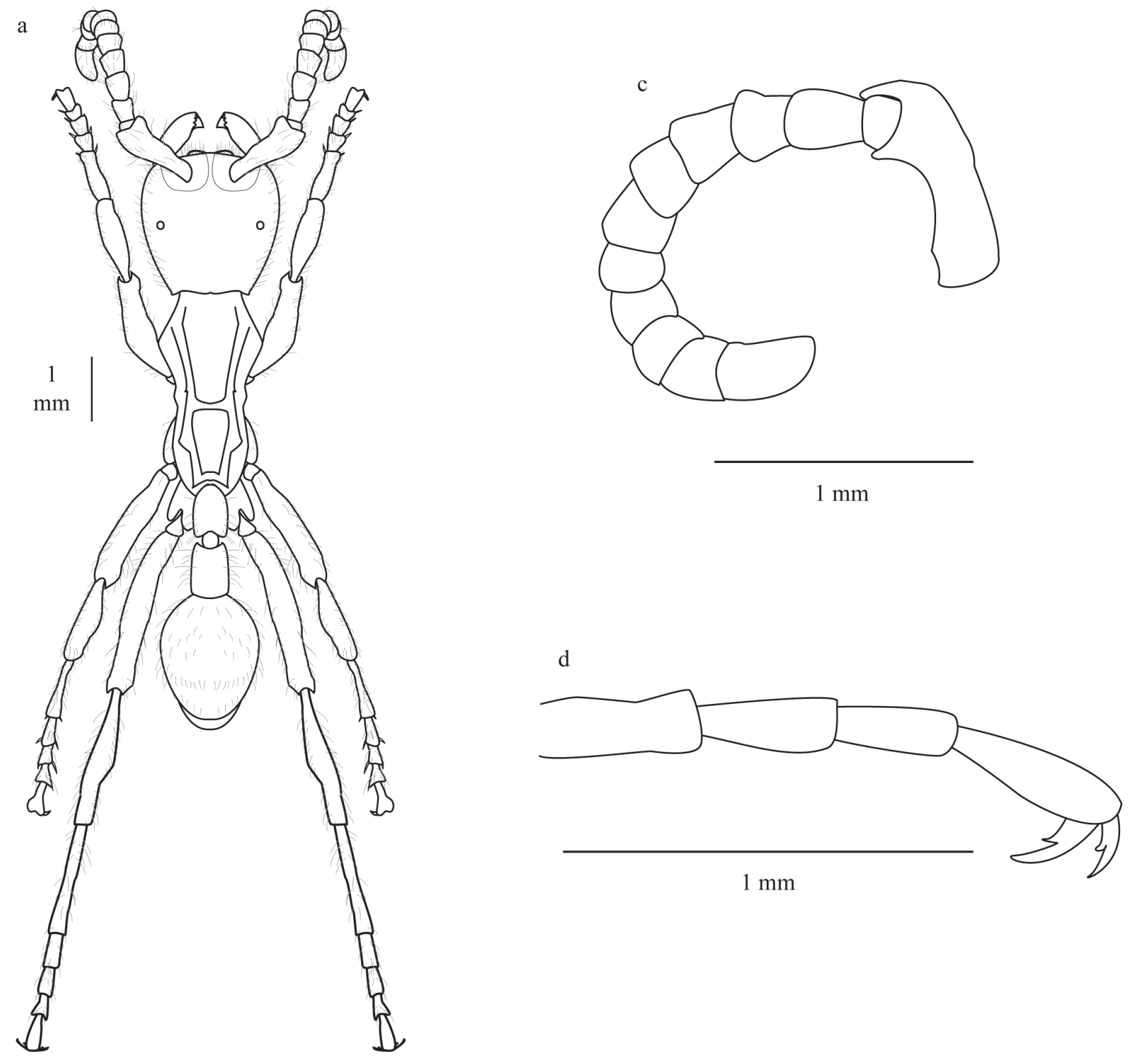

b

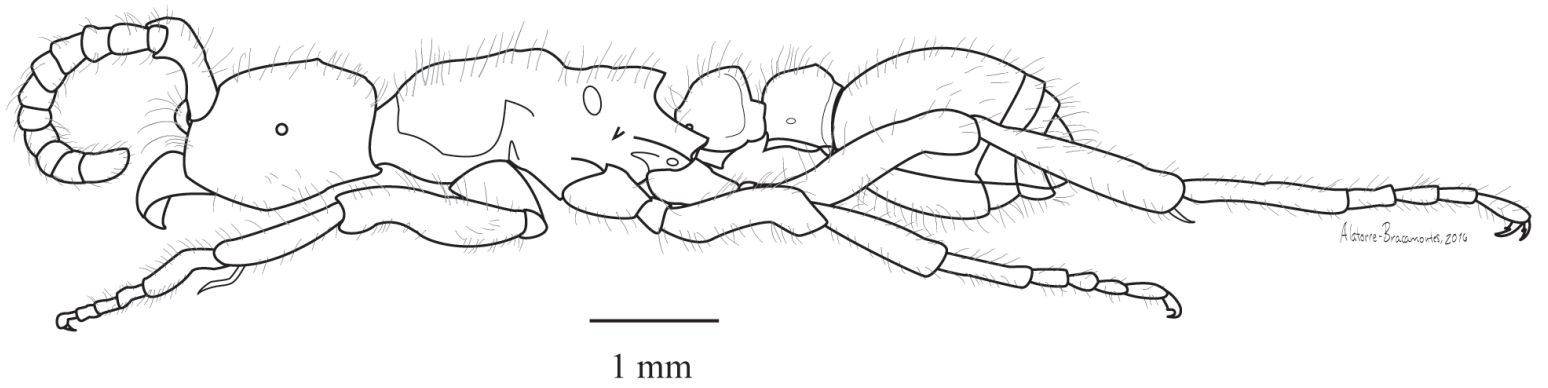

Figura 22. Soldado de Nomamyrmex esenbeckii: a) vista dorsal, b) vista lateral, c) antena (vista lateral), d) dientecillos en las uñas tarsales, metapatas (vista lateral). 